Santa Clara University

Scholar Commons

Civil Engineering

School of Engineering

$4-2010$

\title{
Basin-scale water system operations with uncertain future climate conditions: Methodology and case studies
}

Sebastian Vicuna

John A. Dracup

Jay R. Lund

Larry L. Dale

Edwin P. Maurer

SantaClara University, emaurer@scu.edu

Follow this and additional works at: https://scholarcommons.scu.edu/ceng

Part of the Civil and Environmental Engineering Commons

\section{Recommended Citation}

Vicuna, S., J.A. Dracup, J.R. Lund, L.L. Dale and E.P. Maurer, 2010, Basin-scale water system operations with uncertain future climate conditions: Methodology and case studies, Water Resour. Res., 46, W04505, doi:10.1029/2009WR007838.

Copyright (c) 2010 by the American Geophysical Union. AGU allows final articles to be placed in an institutional repository 6 months after publication.

This Article is brought to you for free and open access by the School of Engineering at Scholar Commons. It has been accepted for inclusion in Civil Engineering by an authorized administrator of Scholar Commons. For more information, please contact rscroggin@scu.edu. 


\title{
Basin-scale water system operations with uncertain future climate conditions: Methodology and case studies
}

\author{
Sebastian Vicuna, ${ }^{1}$ John A. Dracup, ${ }^{2}$ Jay R. Lund, ${ }^{3}$ Larry L. Dale, ${ }^{4}$ and Edwin P. Maurer ${ }^{5}$ \\ Received 10 February 2009; revised 21 July 2009; accepted 3 November 2009; published 16 April 2010. \\ [1] The old and useful paradigm used by water resource engineers, that hydrology in a \\ given place is stationary, and hence it is sufficient to look into the past to plan for the \\ future, does not hold anymore, according to climate change projections. This becomes \\ especially true in snow-dominated regions like California, where not only the magnitude \\ but also the timing of streamflow could be affected by changes in precipitation and \\ temperature. To plan and operate water resources systems at the basin scale, it is necessary \\ to develop new tools that are suited for this nonstationary world. In this paper we \\ develop an optimization algorithm that can be used for different studies related to climate \\ change and water resources management. Three applications of this algorithm are \\ developed for the Merced River basin. The first of these gives an assessment of the climate \\ change effects on the operations of this basin considering an adaptive management \\ strategy embedded in the optimization algorithm. In a second application we explore \\ different long-term adaptation strategies intended to mitigate the effects of climate change. \\ A final application is developed to determine how beneficial it is to build a new reservoir \\ considering explicitly the uncertainty about future climate projections.
}

Citation: Vicuna, S., J. A. Dracup, J. R. Lund, L. L. Dale, and E. P. Maurer (2010), Basin-scale water system operations with uncertain future climate conditions: Methodology and case studies, Water Resour. Res., 46, W04505, doi:10.1029/2009WR007838.

\section{Introduction}

[2] The operation and planning of basin-scale water resources systems has historically relied on assuming stationary hydrologic conditions. This approach assumes that past hydrologic conditions are sufficient to guide the future operation and planning of water resources systems and infrastructure. This assumption is threatened nowadays by climate change and the notion that both climate and hydrology will evolve in the future. New approaches are desirable to address nonstationary and uncertain future hydrology in operating and planning water resources systems [Milly et al., 2008].

[3] This need is especially clear in snow-dominated regions which are expected to be severely affected by climate warming [Barnett et al., 2005]. One such region is the California Sierra Nevada, where studies suggest that although there is still great uncertainty about the magnitude of future hydrologic changes [Maurer and Duffy, 2005; Dettinger,

\footnotetext{
${ }^{1}$ Centro Interdisciplinario de Cambio Global UC, Pontificia Universidad Católica de Chile, Santiago, Chile.

${ }^{2}$ Department of Civil and Environmental Engineering, University of California, Berkeley, California, USA.

${ }^{3}$ Civil and Environmental Engineering Department, University of California, Davis, California, USA.

${ }^{4}$ Environmental Energy Technologies Division, Lawrence Berkeley National Laboratory, University of California, Berkeley, California, USA.

${ }^{5}$ Civil Engineering Department, Santa Clara University, Santa Clara, California, USA.
}

Copyright 2010 by the American Geophysical Union 0043-1397/10/2009WR007838
2005; Vicuna and Dracup, 2007], almost all projections show an increase in temperature shifting seasonal streamflow timing, affecting the management and performance of California's water resources systems.

[4] Several studies have examined the potential impacts of climate change on water resources in California. Most have relied on projections from only one or a few climate scenarios and thus have developed adaptation strategies that might not be robust enough to accommodate a range of climate change scenarios or to provide a more rigorous probabilistic representation of our current understanding of the future climate [Dessai and Hulme, 2007]. With a few exceptions, most have been narrowly formulated impact studies using simulation models to assess the effects of climate on current operating policy (perhaps with a few changes) for a few system components. For example, Van Rheenen et al. [2004] examined several changes to flood control rule curves for reservoir releases to lessen the effects of climate change represented by the National Center for Atmospheric Research (NCAR)'s Parallel Climate model (PCM). Using a reservoir operation optimization, Yao and Georgakakos [2001] developed an integrated forecast decision system to assess the sensitivity of reservoir performance to various forecast management schemes under historical and future climate scenarios. Their assessments were based on results from only one general circulation model (GCM), the Canadian Center for Climate Modeling and Analysis model. Finally, Tanaka et al. [2006] and Medellin-Azuara et al. [2006] explored, using an economic engineering optimization model of California's statewide water supply system (CALVIN), a series of adaptation strategies (ranging from new infrastructure to operational policies) to cope with 


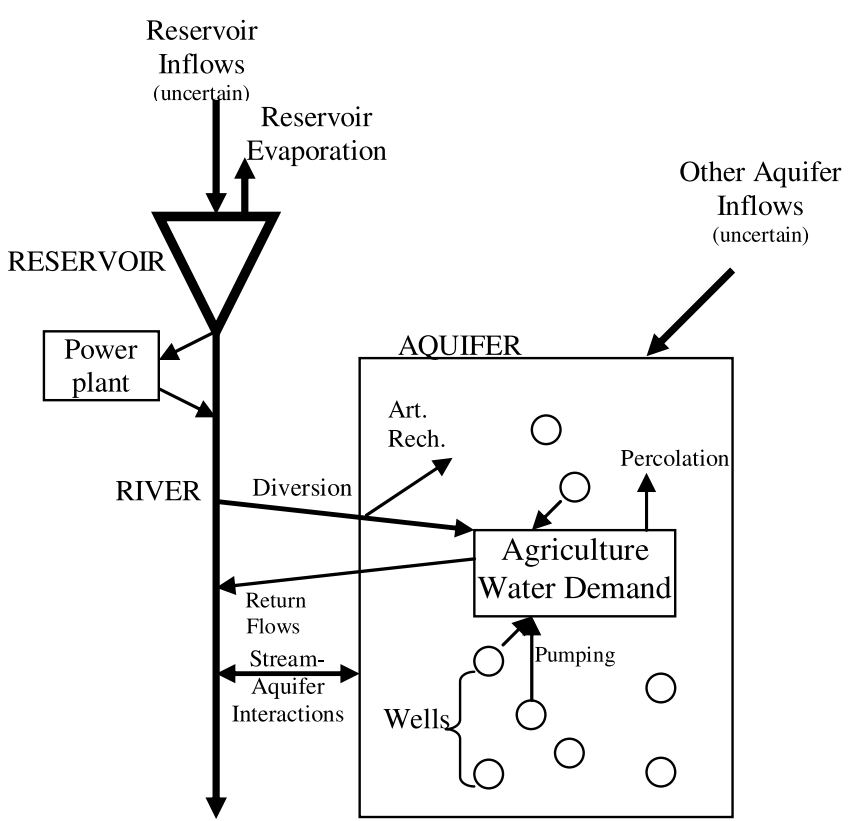

Figure 1. Basic system representation.

the impacts projected by climate change scenarios. Both studies considered few climate change projections. Tanaka et al. [2006] considered run B06.06 from the PCM model (a dry scenario) and run 1 from the Hadley Centre Climate Model 2 (HadCM2, a wet scenario); Medellin-Azuara et al. [2006] considered the impacts associated with the Geophysical Fluid Dynamics Laboratory (GFDL) model run under the A2 greenhouse emission scenarios.

[5] In this paper we present an optimization algorithm that explicitly accounts for probabilistic uncertainty of climate change projections, and hence it could be used in a series of studies related to the operation of a water resources system under future conditions. The paper is organized as follows: section 2 contains the problem formulation and discusses the limitations of previous optimization schemes applied to the operation of water resources systems with climate change conditions. We follow by describing a new optimization method that overcomes some of those limitations. Three applications are made to the Merced River basin in California's San Joaquin Valley. The first application studies the impacts of climate change on the operations of this system. A second case incorporates the study of climate adaptation strategies to the first application. The third application considers a hypothetical example of the use of the tool to study the optimal design of large-scale water resources infrastructure considering the uncertainty about future hydrologic conditions. We finish with some conclusions regarding methodology and applications.

\section{Problem Formulation}

[6] Our interest is to develop a modeling framework to study the operation under climate change hydrologic conditions of a basin-scale system such as the one depicted in Figure 1. This representative system has the following characteristics.
[7] 1. There are two potential water sources: surface water could be available from a reservoir and groundwater pumping from an aquifer.

[8] 2. The benefits from water use vary with the nature of the problem. Benefits could include hydropower revenues from reservoir releases through turbines and/or revenues from irrigated crops. The only costs considered would be pumping costs (other costs are assumed to be negligible or fixed).

[9] 3. Streamflows are uncertain, with two dimensions attached to this uncertainty. There is short-term inherent interannual variability and uncertainty about the next period's hydrologic conditions. Climate change introduces a second uncertainty related to possible climate changes in a particular region. The first type of uncertainty can be treated as a random but stationary process; that is, the statistical properties of the annual and monthly or daily inflow distributions are not changing with time. However, the second type is nonstationary; that is, these properties evolve with time.

[10] Let us now define some variables in the problem formulation. State variables are represented by vector $\mathbf{X}_{t}$ and control or decision variables by vector $\mathbf{U}_{t}$. The state variables are $H_{m}^{A}$ and $S_{m}^{R}$, the stock of water in the aquifer (as aquifer head) and in the reservoir (storage volume) at the beginning of month $m$. Of the four control variables, $P_{m}^{\mathrm{A}}$ denotes the amount pumped by farmers from the aquifer, $R_{m}^{t}$ releases through turbines, $R_{m}^{s}$ spills, and $D_{m}^{a g}$ river diversions for agriculture in month $m$. The benefits and costs of using water in the basin can be formulated using this notation as

$$
\begin{gathered}
\operatorname{AgBenefits}_{m}=\beta_{m}^{a g} *\left(P_{m}^{A}+\varepsilon D_{m}^{a g}\right)-\frac{\gamma_{m}^{a g}}{2} *\left(P_{m}^{A}+\varepsilon D_{m}^{a g}\right)^{2} \\
\text { GenBenefits }_{m}=\alpha_{m}^{R} * f\left(R_{m}^{t}\right) * H^{R}\left(S_{m}^{R}\right)
\end{gathered}
$$$$
\text { PumpCosts }_{m}=P_{m}^{A} * K_{1} *\left(\text { Surface }-H_{m}^{A}\right) * c p_{m},
$$

where $\beta_{m}^{a g}$ and $\gamma_{m}^{a g}$ are parameters related to the assumed linear demand function (quadratic benefit function) for water in the farm; $\varepsilon$ is water use efficiency equal to 1 (the proportion of recoverable losses or seepage that may be later available as groundwater); $P_{m}^{A}+\varepsilon D_{m}^{a g}$ is total water delivery at the farm; $\alpha_{m}^{R}$ equals $K_{2}{ }^{*} c_{m}$, which is a parameter that takes into account monthly energy prices $c_{m}$ and the appropriate unit transformation; $f\left(R_{m}^{t}\right)$ is the effect of releases in energy generation considering efficiency; $H^{R}\left(S_{m}^{R}\right)$ is head in the reservoir as a function of storage; $K_{1}$ is unit conversion to obtain energy used for pumping; surface is surface elevation; and $c p_{m}$ is pumping energy price assumed here different than generation energy price (could be monthly varying).

[11] The relationship between state (stock) and control variables is expressed through a set of transition equations. The transition equation for reservoir storage is

$$
S_{m+1}^{R}=S_{m}^{R}+\tilde{Q}_{m}-R_{m}^{t}-R_{m}^{s}-\operatorname{NetEvap}_{m}\left(S_{m}^{R}\right)
$$

where $\tilde{Q}_{m}$ is monthly inflow to the reservoir, a stochastic variable at the annual time scale, and $\operatorname{NetEvap}_{m}\left(S_{m}^{R}\right)$ is net evaporation from the surface reservoir, a function of the water quantity stored. 
[12] Similarly, there is a relationship between the change in aquifer head and pumping levels and total applied water on the farm described in the following equation:

$$
H_{m+1}^{A}=H_{m}^{A}+\frac{\Delta S_{m}^{A}\left(P_{m}^{A}, D_{m}^{a g}\right)}{A * S^{y}}
$$

where $\Delta S_{m}^{A}$ is the change in storage in the aquifer, a function of the amount of pumping occurring and applied water at the farm, and $A$ and $S^{y}$ are the area and specific yield/storage of the aquifer, respectively, that permit estimation of changes in head/water level for a change in storage.

[13] Depending on the nature of the problem, there could be different objective functions, constraint sets, and transition equations. For example, we could look at this problem from the perspective of a district which controls both reservoir and aquifer operations (equivalent to a social planner in resource economics literature). In this case we would consider all costs and benefits in the objective function as well as the dynamics of both systems as part of the constraints set. We could also consider this problem only from the reservoir operator perspective, in which although one considers the farm benefits as part of the problem formulation, one cannot control how farm pumping responds to the amount of water in the river for diversion (see Vicuna [2007] for other problem formulations). The general optimization problem (described here at an annual time scale) to be solved is

$$
\begin{aligned}
& \underset{\mathbf{U}_{t}}{\operatorname{Max}}\left\{\underset{\mathbf{Q}}{\mathrm{E}}\left[\sum \mathrm{NetBenefits}_{t}\left(\mathbf{X}_{t}, \mathbf{U}_{t}\right)\right]\right\} \\
& \text { st } \\
& \mathbf{U}_{t} \in(\Theta \otimes \Pi) \text { (constraints) } \\
& \mathbf{X}_{t+1}=\mathbf{T}\left(\mathbf{X}_{t}, \mathbf{U}_{t}, \tilde{Q}_{t}\right) \text { (transition equations), }
\end{aligned}
$$

where $\underset{\mathbf{Q}}{\mathrm{E}}[\cdots]$ is the expectation operator, included because the hydrologic conditions represented here by $\tilde{Q}_{t}$ are stochastic in nature, and $\Theta \otimes \Pi$ is the bivariate space of constraints for both $\mathbf{X}_{t}$ and $\mathbf{U}_{t}$.

[14] Some complexities of this problem formulation include: (1) letting hydropower generation and pumping costs vary with head makes the objective function nonlinear and, unless some approximations are introduced (e.g., quasilinearization), prevents using linear programming to solve the problem; and (2) the stochastic nature of reservoir inflows has the added difficulty of being nonstationary when considering climate change.

[15] Stochastic dynamic programming (SDP) is a powerful technique widely used in water resources optimization [Yakowitz, 1982; Yeh, 1985; Labadie, 2004; Lee and Labadie, 2007] that can deal with the first level of complexity and work with nonlinearities in the problem formulation. It also could be used to treat stochastic variables such as reservoir inflows. However, in its classic approach, SDP assumes that these variables follow a stationary process, so it cannot be used for climate change conditions. The approach we suggest in section 2 is a derivative of SDP known as sampling stochastic dynamic programming (SSDP) [Kelman et al., 1990; Faber and Stedinger, 2001]. In section 3 we describe the SSDP algorithm and some other innovations to explore long-term operations in a basin-scale water resources system explicitly considering the uncertainties associated with different climate projections.

\section{Solution Method}

[16] The approach suggested is based primarily on the technique introduced by Kelman et al. [1990] known as SSDP and described later. It shares some aspects of the approach used by Vedula and Kumar [1996] and the idea of nesting optimization models to accommodate differences between the temporal scales of the stochastic variables and of the decision variables as explained.

\subsection{Sampling Stochastic Dynamic Programming}

[17] Overcoming the limitations of SDP mentioned earlier, SSDP is promising for climate change impact and adaptation studies. One advantage over SDP is that the technique does not rely on a given probabilistic description of inflows and thus can handle nonstationary hydrologic processes. The technique has been used to optimize real-time operations of reservoirs using ensembles of continuously updated forecasted inflow scenarios [Faber and Stedinger, 2001; Kelman et al., 1990]. SSDP is similar to SDP, although in this technique the uncertainty is represented by intact scenarios of hydrographs representing persistence and nonstationarity conditions. In SSDP the transition in the Bellman equation is not between discrete representations of inflow conditions but between a discrete number of intact hydrologic scenarios. This can be appreciated by comparing the basic mathematical formulations of the approaches in equation (7) (classic SDP) and equation (8) (SSDP):

$$
\begin{aligned}
F^{t}\left(\mathbf{X}_{t}, Q_{h}^{t}\right)= & \underset{\mathbf{U}_{t} \in(\Theta \otimes \Pi)}{\operatorname{Max}} \\
& \cdot\left\{\mathbf{B}_{t}\left(\mathbf{X}_{t}, \mathbf{U}_{t}, Q_{h}^{t}\right)+\beta \underset{\mathbf{Q}_{t+1}}{\mathrm{E}}\left[F^{t+1}\left(\mathbf{X}_{t+1}, \mathbf{Q}_{t+1}\right)\right]\right\},
\end{aligned}
$$

$\forall \mathbf{X}_{t}, Q_{h}^{t}$,

where $F^{t}\left(\mathbf{X}_{t}, Q_{h}^{t}\right)$ is the value function for a given state and inflow condition and $\underset{\mathbf{Q}_{\mathbf{t}+\mathbf{1}}}{\mathrm{E}}\left(F^{t+1}\left(\mathbf{X}_{t+1}, \mathbf{Q}_{t+1}\right)\right)=\sum_{k=1}^{k=n} p\left(Q_{t+1}=Q_{k}\right) *$ $F^{t+1}\left(\mathbf{X}_{t+1}, Q_{k}\right)=\mathbf{P}_{Q k}^{t} F^{t+1}\left(\mathbf{X}_{t+1}, Q_{t+1, k}\right)$ is the expectation of next period's value function which can be calculated by multiplying the probability of given inflow category $(k)$ to its associated value function:

$$
\begin{aligned}
& U_{t}^{o p t}\left(\mathbf{X}_{t}, i\right) \\
& \quad=\arg \left(\operatorname{Max}_{\mathbf{U}_{t} \in(\Theta \otimes \Pi)}\left\{\mathbf{B}_{t}\left(\mathbf{X}_{t}, \mathbf{U}_{t}, \mathbf{Q}_{t}(i)\right)+\beta \underset{j / i}{\mathrm{E}}\left[F^{t+1}\left(\mathbf{X}_{t+1}, j\right)\right]\right\}\right) \\
& F^{t}\left(\mathbf{X}_{t}, i\right)=\mathbf{B}_{t}\left(\mathbf{X}_{t}, U_{t}^{o p t}\left(\mathbf{X}_{t}, i\right), \mathbf{Q}_{t}(i)\right)+\beta F^{t+1}\left(\mathbf{X}_{t+1}, i\right) \\
& \forall \mathbf{X}_{t}, i \text { and } t \in\{1, \ldots, T\}
\end{aligned}
$$

where $\underset{j / i}{\mathrm{E}}\left[F^{t+1}\left(\mathbf{X}_{t+1}, j\right)\right]=\mathbf{T} \mathbf{P}_{j^{t+1} / i^{t}}^{t} * F^{t+1}\left(\mathbf{X}_{t+1}, j\right)$ is the expectation of next year's hydrologic scenario given that we are in this year in scenario $i$. In this equation, $\mathbf{T P}_{j^{t+1} / i^{t}}^{t}$ is the transition 
probability matrix of inflow projections in year $t+1$ given projection $i$ in year $t$.

[18] As Turgeon [2007] points out, the devil with SSDP is in the details of the transition probabilities. Different types of transitions between scenarios were studied by Faber [2000], ranging from the deterministic case having no real transition between scenarios to a more probabilistic approach, in which the state of the system determines a probabilistic function of future scenarios to which the system could move on the basis of historical forecasts. In the climate change case, no real-time forecast scenarios exist, but there are ensembles of different GCM results for different greenhouse gas (GHG) emission scenarios that represent projections of possible future conditions. These projections could be used in a SSDP approach, as Faber and Stedinger [2001] used ensemble streamflow prediction (ESP) forecasts to determine real-time operation rules. Transition probabilities in this case can be estimated from the statistical properties of these scenarios over time. To consider that climate change projections tend to diverge over time, we developed transition probabilities that evolve over time, allowing some movement between scenarios in early years but moving to more deterministic transitions later. Appendix A describes the approach used to estimate transition probabilities.

[19] A series of decisions is needed to develop these matrices that affect the performance of the SSDP approach. In general, the ideal set of transition probability matrices would be such that at each time and for each climate change projection, the expectation part of the dynamic programming equation $\left(\mathbf{T P}_{j^{t+1}}^{t} / i^{t} * F^{t+1}\left(\mathbf{X}_{t+1}, j\right)\right)$ will consider some uncertainty in future hydrologic conditions with an average condition from the climate change scenario under consideration. Consider, for example, that we are solving the Bellman equation (equation (8)) for a given climate projection in year 2050. Consider also that in a cumulative sense that particular projection up to that point in time is drier than average historical conditions. The solution in terms of reservoir operations should take into account future hydrologic conditions that would likely also be drier than average but should consider some variability around this expected condition. Otherwise the model will be solving a deterministic problem which is undesired if we want to represent remaining uncertainty. Including a larger set of climate change scenarios increases the chances of transitioning to more than one scenario at any time/stage. It also helps to have a small number of possible discrete percentiles in the range of cumulative anomalies (used to determine the frequency of changes among percentile levels, as shown in Appendix A) because this increases the possibility of including more projections at any one of these levels and hence increase the richness of the hydrologic conditions to be considered in the expectation part of the Bellman equation. In the case studies presented next, after some exploratory analysis, we decided to divide the inflow cumulative anomalies into three groups to represent transition probabilities.

\subsection{Monthly Nonlinear Formulation}

[20] The stochastic nature of the problem is considered in these transition probability matrices between climate change projections at any given point. These transition probabilities occur at an annual time scale; however, the most interesting effects of climate change on snow-dominated regions are those affecting seasonal streamflow timing. So it is necessary to include monthly conditions of streamflow and decisions in the formulation of objectives and dynamics. For this we use Vedula and Kumar's [1996] approach, embedding a monthly nonlinear deterministic programming model within the SSDP stochastic formulation. With this approach we implicitly represent the control variable $\mathbf{U}_{t}$ (e.g., annual releases in the reservoir) by annual changes in the state variable (e.g., reservoir storage). By using a deterministic framework for the monthly operations of the system, we recognize that this formulation will somewhat overestimate benefits compared to real operators who must make decisions without such prescience. Thus our methodology is not suited to real-time operations, but it proves very useful for longterm impact and infrastructure decisions.

[21] The structure of the annual SSDP with the embedded monthly nonlinear programming model is shown below. We first modified the basic SSDP equation (see equation (8)) to express indirectly the decision controls as a function of the initial and final states of the state vector. The annual benefits in this formulation are replaced by the result of a monthly time step nonlinear optimization problem with border conditions equal to the initial and final states as prescribed in the original value function formulation.

$$
\begin{aligned}
& l_{t}^{\mathrm{opt}}(\mathbf{k}, i)=\arg \left(\operatorname{Max}_{l_{t} \in(\Theta \otimes \Pi) *}\left\{\mathbf{B}_{t}^{a}\left(\mathbf{k}, \mathbf{l}, \mathbf{Q}_{t}(i)\right)+\beta \underset{j / i}{\mathrm{E}}\left[F^{t+1}(\mathbf{l}, j)\right]\right\}\right) \\
& F^{t}(\mathbf{k}, i)=\mathbf{B}_{t}^{a}\left(\mathbf{k}, l_{t}^{\text {opt }}(\mathbf{k}, i), \mathbf{Q}_{t}(i)\right)+\beta F^{t+1}\left(l_{t}^{\mathrm{opt}}(\mathbf{k}, i), j\right),
\end{aligned}
$$

where

$$
\begin{aligned}
& \mathbf{B}_{t}^{a}\left(\mathbf{k}, \mathbf{l}, \mathbf{Q}_{t}(i)\right)=\operatorname{Max}_{\mathbf{U}_{1}, \mathbf{U}_{2} . . \mathbf{U}_{12}}\left(\sum_{m=1}^{m=12}\left(\mathbf{B}_{m}\left(\mathbf{X}_{m}, \mathbf{U}_{m}\right)\right)\right) \\
& s t: \\
& \mathbf{X}_{m+1}=\mathbf{T}\left(\mathbf{X}_{m}, \mathbf{U}_{m}, Q_{m}^{i}\right) \\
& Q_{m, t}^{i}=\hat{f}\left(\mathbf{Q}_{t}(i)\right) \\
& \mathbf{X}_{m} \in \Theta ; \mathbf{U}_{m} \in \Pi \\
& \mathbf{X}_{1}=\mathbf{k} ; \mathbf{X}_{12}=\mathbf{l} .
\end{aligned}
$$

Here $\mathbf{k}, \mathbf{l}$ are state vector discrete bins. $\mathbf{B}_{t}^{a}\left(\mathbf{k}, \mathbf{l}, \mathbf{Q}_{t}(i)\right)$ represents the maximum benefit attainable if the state at the beginning of the cycle is $\mathbf{k}$ and at the end of the cycle is $\mathbf{l}$, and annual inflow $\mathbf{Q}_{t}(i)$ corresponds to projection $i$ in year $t$. The result is a nonlinear optimization problem that can be solved earlier. Also, $t, m$ are temporal indices, $t$ at annual and $m$ at monthly scale; $Q_{m, t}^{i}$ is the annual flow of projection $i$ distributed monthly using function $\hat{f}$; and $\beta$ is the discount factor.

[22] Solving $\mathbf{B}_{t}^{a}\left(\mathbf{k}, \mathbf{l}, \mathbf{Q}^{h}\right), \forall \mathbf{Q}^{h}, \mathbf{k}, \mathbf{l}$ (here $\mathbf{Q}^{h}$ corresponds to different classes of annual inflows) provides a surface of benefits that can be approximated using splines to obtain a continuous function $\tilde{\mathrm{B}}\left(\mathbf{k}, \mathbf{l}, \mathbf{Q}^{h}\right)$. Johnson et al. [1993] describe the use of splines. Similarly, $F^{t+1}(\mathbf{l}, j)$ can be 
approximated (again using splines) into $\tilde{F}^{t+1}(\mathbf{l}, j)$. Using these two approximations, the original problem can be solved using nonlinear programming methods, saving computing time and increasing accuracy:

$\tilde{l}_{t}^{\text {opt }}(\mathbf{k}, i)=\arg \left(\underset{l_{t} \in(\Theta \otimes \Pi) *}{\operatorname{Max}}\left\{\tilde{\mathrm{B}}\left(\mathbf{k}, \mathbf{l}, \mathbf{Q}_{t}(i)\right)+\beta \mathbf{T P}_{j^{t+1} / i^{t}}^{t} \cdot \tilde{F}^{t+1}(\mathbf{l}, j)\right\}\right)$.

Vicuna [2007] provides more details on the problem formulation for the application of this algorithm to the case studies presented later.

\subsection{Future Scenarios}

[23] The algorithm allows inclusion of different future operation and configuration scenarios. Some of these scenarios could represent long-term adaptation strategies to mitigate the impacts of climate change on an already developed system configuration. These adaptation strategies include modifying infrastructure or long-term operating policies such as flood control rules. Another example of scenarios could be related to future water resources infrastructure (e.g., building a reservoir). Each future scenario creates a new problem formulation and requires a new nonlinear programming model to determine $\tilde{\mathrm{B}}\left(\mathbf{k}, \mathbf{l}, \mathbf{Q}^{h}\right)$. We introduce this idea by including a new notation $\psi$ to represent these different scenarios. These scenarios could be implemented in different points in time $\left(t_{\text {adapt }}\right)$, allowing the exploration of their marginal benefits as the impacts of climate change become more evident. The different scenarios are combined with different adoption years to create the full set of future scenarios. Including the idea of a future scenario strategy modifies the optimization algorithm presented in equation (9) to the more general format:

$$
\begin{aligned}
& \text { If } t<t_{\text {adapt }} \\
& \begin{array}{l}
l_{t}^{\text {opt }}\left(\mathbf{k}, i, \psi, t_{\text {adapt }}\right) \\
\quad=\arg \left(\operatorname{Max}_{l_{t} \in(\Theta \otimes \Pi) *}\left\{\mathbf{B}_{t}^{a}\left(\mathbf{k}, \mathbf{l}, \mathbf{Q}_{t}(i)\right)+\beta \underset{j / i}{\mathrm{E}}\left[F^{t+1}(\mathbf{l}, j)\right]\right\}\right) \\
\quad F^{t}(\mathbf{k}, i)=\mathbf{B}_{t}^{a}\left(\mathbf{k}, l_{t}^{\text {opt }}\left(\mathbf{k}, i, \psi, t_{\text {adapt }}\right), \mathbf{Q}_{t}(i)\right) \\
\quad+\beta F^{t+1}\left(l_{t}^{\text {opt }}\left(\mathbf{k}, i, \psi, t_{\text {adapt }}\right), j\right),
\end{array}
\end{aligned}
$$

else

$$
\begin{aligned}
& l_{t}^{\text {opt }}\left(\mathbf{k}, i, \psi, t_{\text {adapt }}\right) \\
& =\arg \left(\operatorname{Max}_{l_{t} \in(\Theta(\psi) \otimes \Pi(\psi)) *}\left\{\mathbf{B}_{t}^{a}\left(\mathbf{k}, \mathbf{l}, \mathbf{Q}_{t}(i), \psi\right)+\beta \underset{j / i}{\mathrm{E}}\left[F^{t+1}(\mathbf{l}, j)\right]\right\}\right) \\
& F^{t}(\mathbf{k}, i)=\mathbf{B}_{t}^{a}\left(\mathbf{k}, l_{t}^{\mathrm{opt}}\left(\mathbf{k}, i, \psi, t_{\text {adapt }}\right), \mathbf{Q}_{t}(i), \psi\right) \\
& +\beta F^{t+1}\left(l_{t}^{\text {opt }}\left(\mathbf{k}, i, \psi, t_{\text {adapt }}\right), j\right) .
\end{aligned}
$$

Here $\mathbf{B}_{t}^{a}\left(\mathbf{k}, \mathbf{l}, \mathbf{Q}_{t}(i), \psi\right)$ comes from the results of a nonlinear programming model with the characteristics of scenario $\psi$. The set of constraints $\left(l_{t} \in(\Theta(\psi) \otimes \Pi(\psi))\right)$ also is affected by the given scenario.

\subsection{Simulation of Scenarios}

[24] Using the SSDP algorithm together with a given future scenario (or the base case), we obtain a set of optimal annual operating rules $l_{t}^{\text {opt }}\left(\mathbf{k}, i, \psi, t_{\text {adapt }}\right)$ that depend on the climate change projection and position in the state vector. This rule is then used in a simulation model with the projected hydrologic conditions and given initial conditions to determine the results for a given future scenario. The simulation phase starts with an initial condition $k_{0}=k_{\text {init }}$. Subsequent state levels are obtained considering the optimal operating rules. For example, $k_{1}=l_{1}^{\text {opt }}\left(k_{0}, i, \psi, t_{\text {adapt }}\right)$. In general, $k_{i, t+1}=l_{t}^{\text {opt }}\left(k_{i, t}, i, \psi, t_{\text {adapt }}\right)$. These results correspond to positions in the state vector at annual time scales. Monthly results are obtained by solving the same nonlinear programming model used to obtain $\mathbf{B}_{t}^{a}\left(\mathbf{k}, \mathbf{l}, \mathbf{Q}_{t}(i), \psi\right)$, where now $\mathbf{k}$ is $k_{i, t}$ and $\mathbf{l}$ is $k_{i, t+1}$. The aggregation of the benefits at this monthly scale gives the annual benefits for every time period, climate change projection, adaptation strategy, and adoption time for this strategy: $\operatorname{Ben}_{t}\left(i, \psi, t_{\text {adapt }}\right)$. To compare among adaptation strategies, we estimate at a given $t_{\text {adapt }}$ the average net annual benefits for all projections considering a discretionary number of years into the future (30 years were later used in the applications).

[25] Comparing the average net benefits for different future strategies and times of adoption and climate change projections, we get an estimate of the value of the different strategies and their statistical properties. Some strategies could be valuable under some projections but not for others, potentially having a detrimental effect, so this needs to be assessed statistically considering the average net benefits over all projections.

[26] Figure 2 is a summary schematic for the approach. In sections 4-7 we apply this optimization algorithm in three studies of the climate change impacts on water resources in the Merced River basin in California.

\section{Case Study: Merced River Basin, California}

\subsection{Merced River Basin}

[27] The Merced River basin (MRB) is in the eastern San Joaquin Valley in central California. Lake McClure regulates streamflow in the Merced River behind New Exchequer Dam with a capacity of 1260 million cubic meters (MCM) (or 1025 thousand acre feet (TAF)), slightly above the mean annual inflow to the reservoir $(\sim 1170 \mathrm{MCM}$ (950 TAF)). The Merced Irrigation District (MID) operates New Exchequer Dam and distributes the diverted water for farmers within its service area. Water released from the reservoir flows through hydropower turbines (up to a capacity), with the generated energy being sold. Farmers within the MID also rely on groundwater from the Merced groundwater basin [California Department of Water Resources, 2003]. This aquifer extends over 160 thousand hectares (400 thousand acres) and is the sole water supply for farmers outside the district's service area.

[28] Using the MRB, we developed three examples of the potential applications of the method described. In the first application we considered the existing system being operated in the MRB and assess the impacts of climate change hydrologic conditions. A second application expands this analysis considering adaptation strategies to reduce such impacts. A third application explores a hypothetical case in which New Exchequer did not exist and the basin managers are asked whether they should build a reservoir, and if so, what is the optimal size of such a reservoir. 
Annual SSDP model with non-linear optimization model embedded and climate change transition probabilities

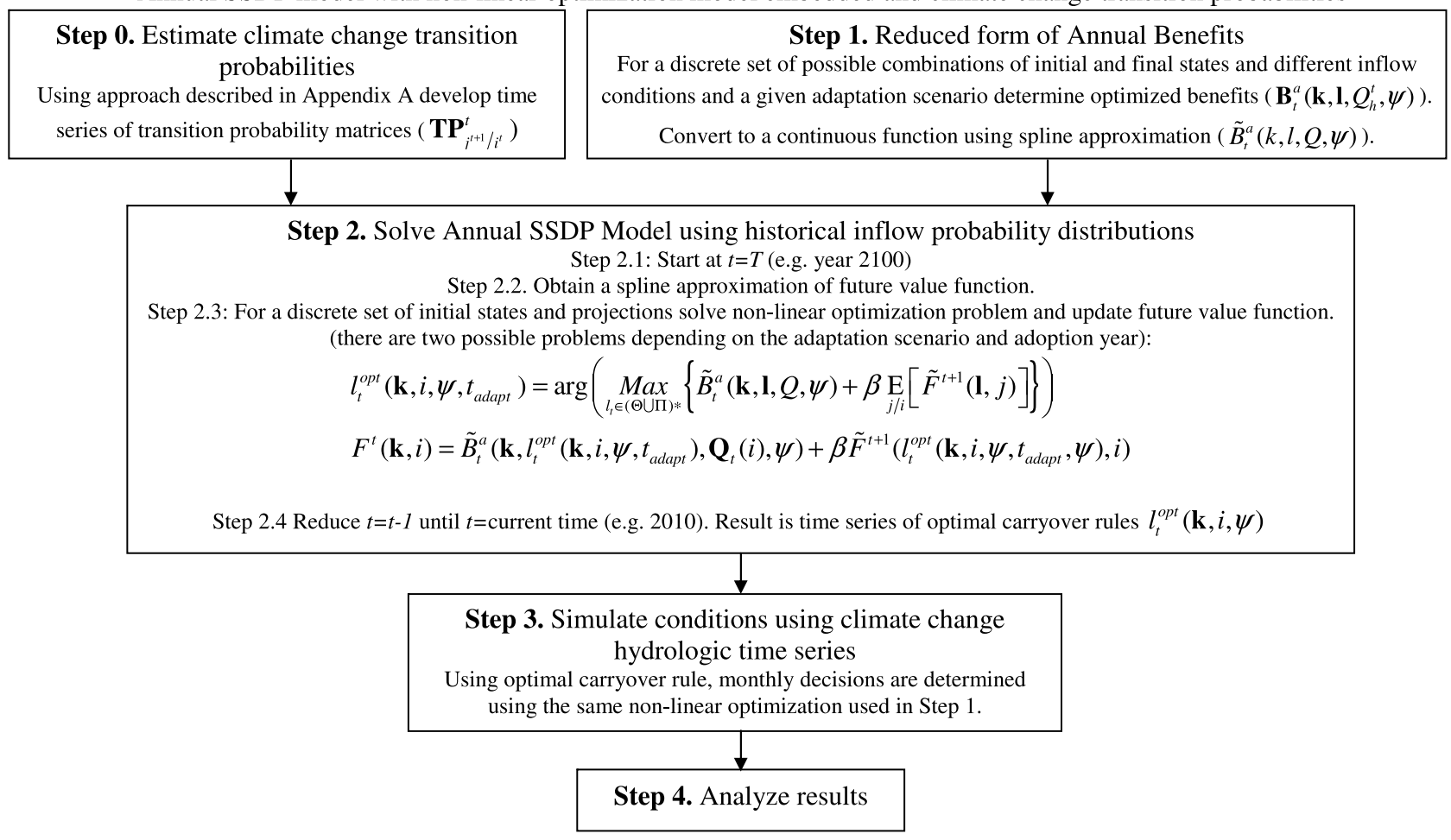

Figure 2. Algorithm flowchart.

\subsection{Climate Change Hydrologic Conditions}

[29] Similarly to other basins in the California Sierra Nevada, the MRB would be affected by climate change [Dettinger et al., 2004]. In this work the hydrologic conditions with climate change were derived using the outputs of eleven GCMs run under two GHG emission scenarios (the higher A2 and lower B1). The same projections, listed in Table 1, were used to assess uncertainty of climate change projections in California by Maurer [2007]. These climate data were statistically downscaled following a method explained in the work of Maurer [2007] and input to the variable infiltration capacity (VIC) model to obtain a time series of monthly streamflow conditions for MRB at Lake McClure. The data series start in 1961 and end in 2100.

[30] Figure 3 shows how the projected increase in temperature by all GCMs is expected to affect streamflow timing in the Merced River (represented by the center of mass of the hydrograph over the October to September water year). There is also uncertainty in the annual streamflow volume. Figure 4 shows a time series of cumulative anomalies of annual inflows for each GCM projection. Figure 4 illustrates the variability of projected hydrologic conditions for the basin, with models projecting clear increases or decreases in the annual flow. These projected hydrologic conditions are the basis for transition proba-

Table 1. General Circulation Models Included in This Study ${ }^{\mathrm{a}}$

\begin{tabular}{|c|c|c|}
\hline Modeling Group and Country & $\begin{array}{l}\text { Intergovernmental Panel on } \\
\text { Climate Change Model }\end{array}$ & ID Abbreviation \\
\hline Météo-France/Centre National de Recherches Météorologiques, France & CNRM-CM3 & Cnrm \\
\hline CSIRO Atmospheric Research, Australia & CSIRO-Mk3.0 & Csiro \\
\hline $\begin{array}{l}\text { U.S. Department of Commerce, NOAA, Geophysical Fluid Dynamics } \\
\text { Laboratory, USA }\end{array}$ & GFDL-CM2.0 & Gfdl \\
\hline NASA Goddard Institute for Space Studies, USA & GISS-ER & Giss \\
\hline Institute for Numerical Mathematics, Russia & INM-CM3.0 & Inmcm \\
\hline Institut Pierre Simon Laplace, France & IPSL-CM4 & Ipsl \\
\hline $\begin{array}{l}\text { Center for Climate System Research, University of Tokyo, National Institute } \\
\text { for Environmental Studies, } \\
\text { and Frontier Research Center for Global Change, JAMSTEC, Japan }\end{array}$ & MIROC3.2 & Miroc \\
\hline Max Planck Institute for Meteorology, Germany & ECHAM5/MPI-OM & Mpi \\
\hline Meteorological Research Institute, Japan & MRI-CGCM2.3.2 & Mri \\
\hline National Center for Atmospheric Research, USA & PCM & Pcm \\
\hline Hadley Centre for Climate Prediction and Research/Met Office, UK & UKMO-HadCM3 & hadcm 3 \\
\hline
\end{tabular}

${ }^{\mathrm{a}}$ From Maurer [2007]. 


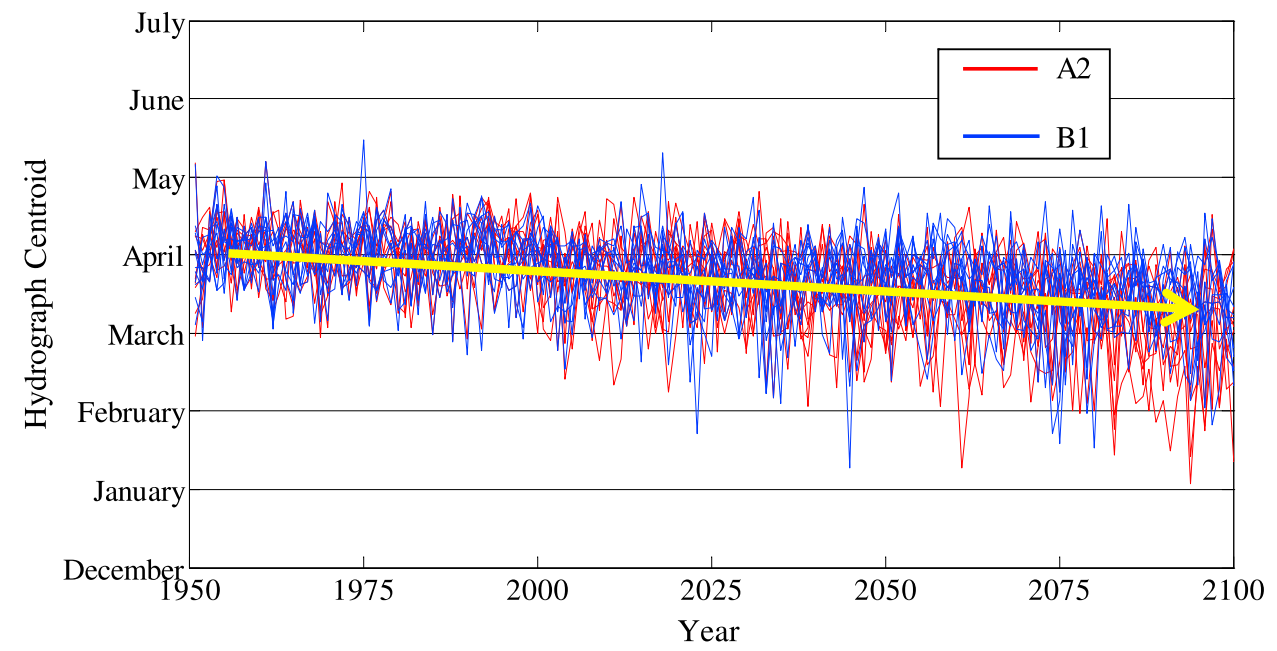

Figure 3. Time series of Merced River hydrograph center of mass as projected by a set of climate change scenarios.

bility matrices for each point in time and each climate change scenario as explained in Appendix A.

\section{First Application: Climate Change Impacts on Merced River Basin Operations}

[31] In this first application we explore the effects of climate change on the operation of the MRB. Using the transition matrices developed from the climate change projections (step 0 of the algorithm in Figure 2) and estimates of annual benefit functions from a series of nonlinear monthly optimization problems (step 1 in algorithm, simulating monthly operations for a water year) representing the operation configuration of the Merced River basin, we applied the SSDP algorithm to obtain operating rules at any point in time for all of the 22 climate change projections. These rules then were used in a simulation model to obtain base case water impact results of climate change for the Merced River basin. Figures 5-8 summarize some results for this base case. Figure 5 shows the time series of net annual benefits under all climate change projections, showing the average for all projections and the maximum and minimum values, along with the average benefits with historical hydrologic conditions. There is a large uncertainty in the impacts of climate change in this basin. Some projections suggest an improvement, while others suggest a reduction in benefits. On average, before year 2050, annual benefits are almost indistinguishable from the historical values, but starting around this year, a steady decline occurs in benefits reaching almost 20\% ( $\$ 5$ million/yr) by the end of the 21 st century compared with historical conditions.

[32] Results for three points in time, the early, middle, and late 21 st century, are used to explore how decision and state variables evolve with climate change. Figure 6 summarizes decision results for reservoir turbine releases, spills, river diversion, and groundwater pumping. From Figures $6 \mathrm{a}$ and $6 \mathrm{~b}$, changed hydrologic conditions have several effects on system operations. For reservoir operations the typically

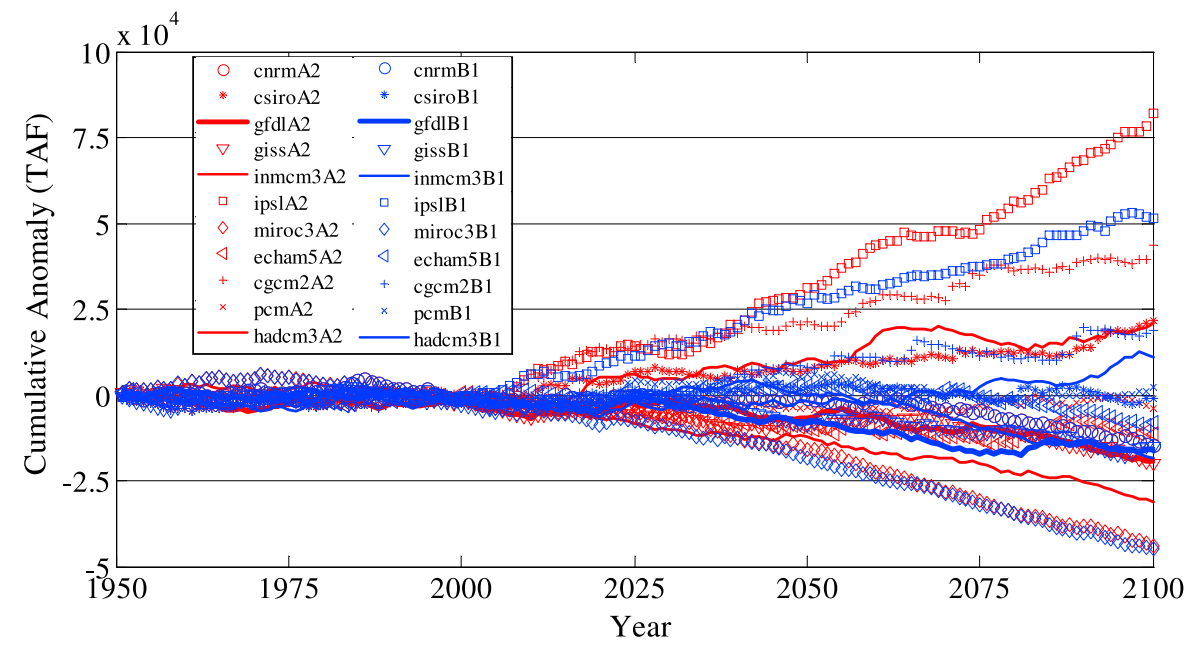

Figure 4. Time series of cumulative anomalies of annual inflows for Merced River at Lake McClure according to 22 climate change projections. 


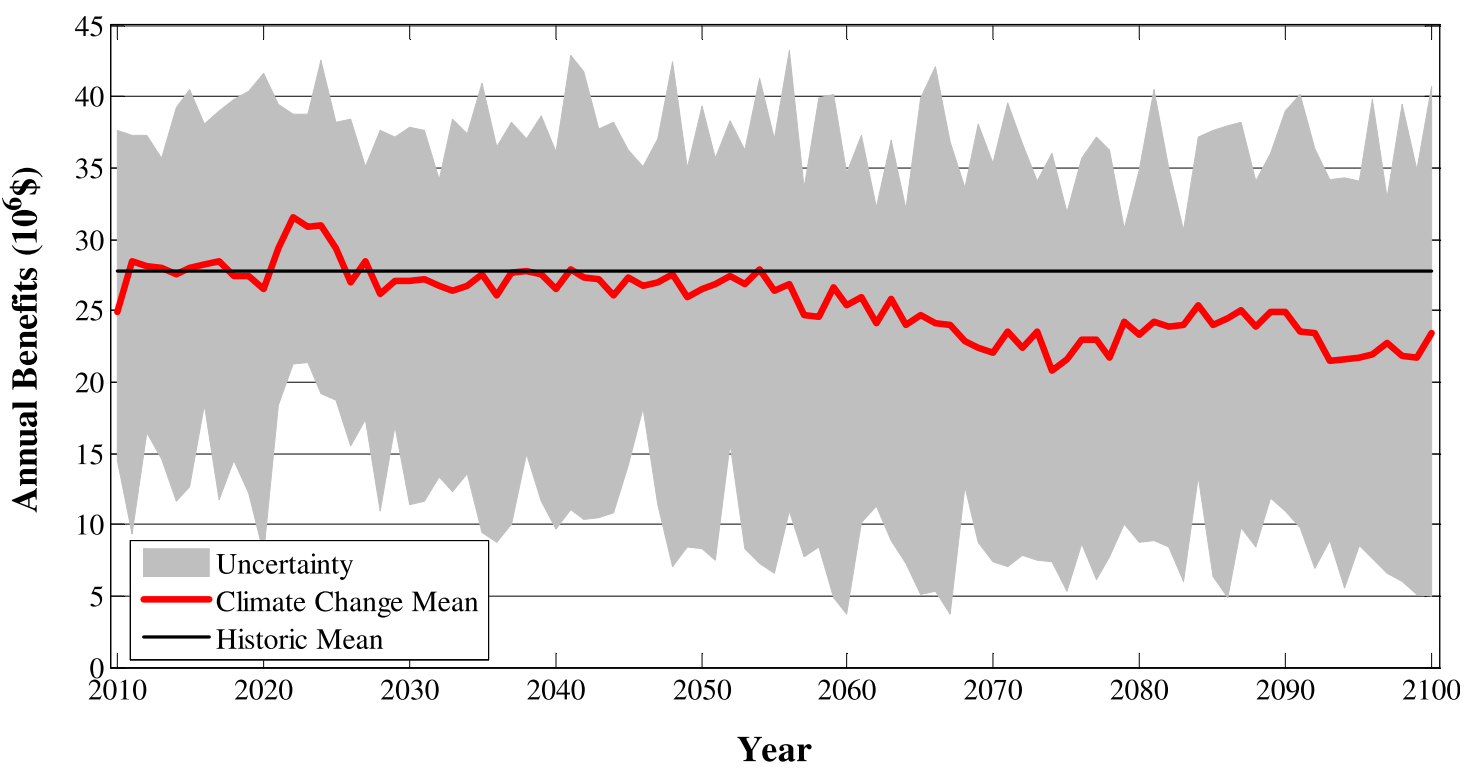

Figure 5. Time series of annual benefits for all climate change projections derived through a simulation of operations using optimal rules obtained following the Sampling Stochastic Dynamic Programming nonlinear programming algorithm.

reduced amount and earlier timing of inflows reduces releases, especially during the later spring and summer (when water is more valuable for hydropower and irrigation), but increases releases in later winter and early spring as spills with little value for use. Reduced releases in spring and summer are accompanied by reduced river diversions for farm irrigation (see Figure 6c). These reduced surface diversions increase groundwater pumping for crop irrigation (Figure 6d).

[33] The effect of these decisions on the state variables appears in Figures 7 and 8. Figure 7 shows the reduction in reservoir storage from reduced reservoir inflows. This reduction is clearer in the summer, whereas the later spring has little change, again because of the earlier timing of
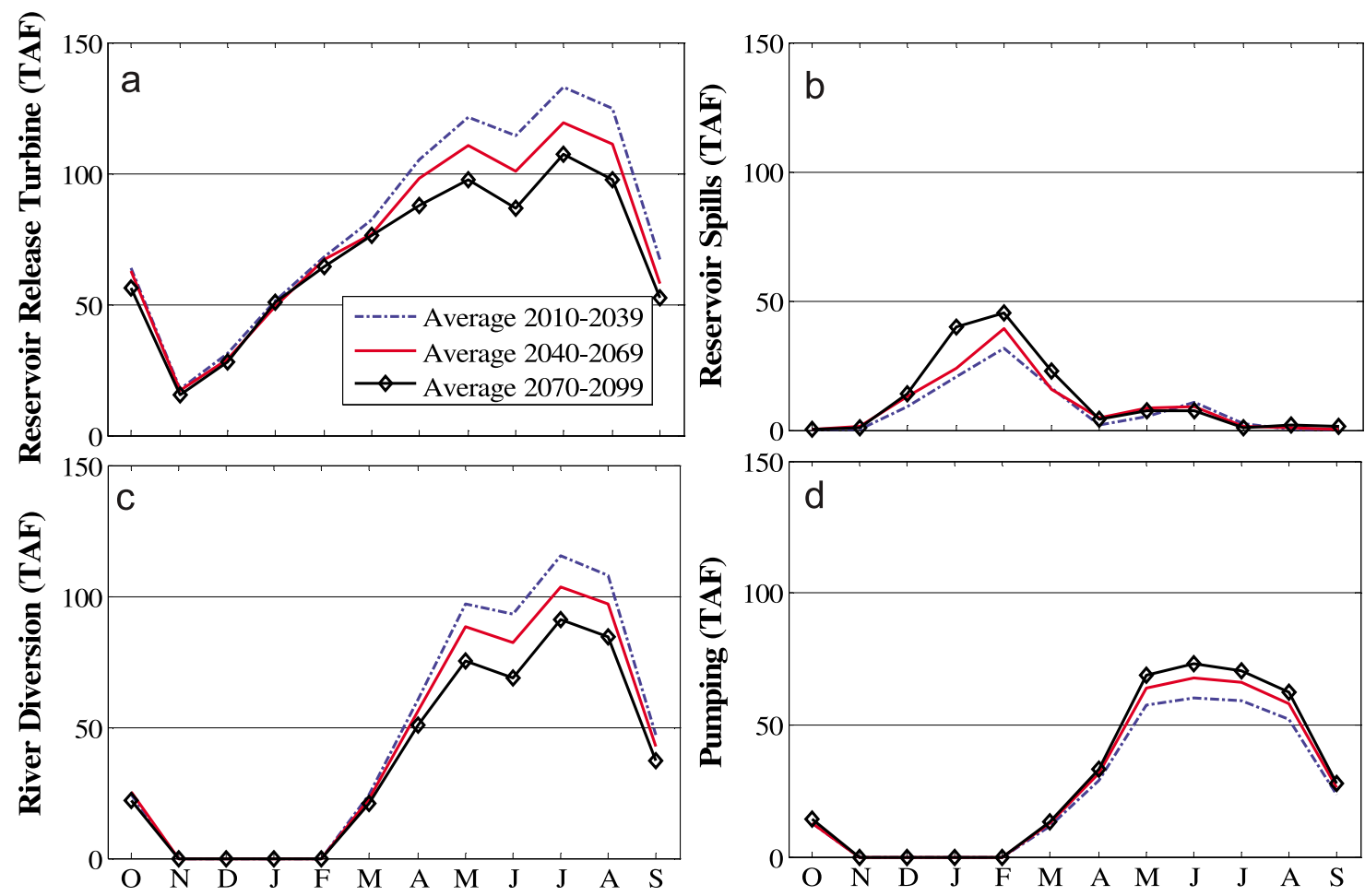

Figure 6. Average system operations for all climate change projections: (a) reservoir releases through turbines, (b) spills, (c) river diversion, and (d) groundwater pumping. TAF, thousand acre feet. 


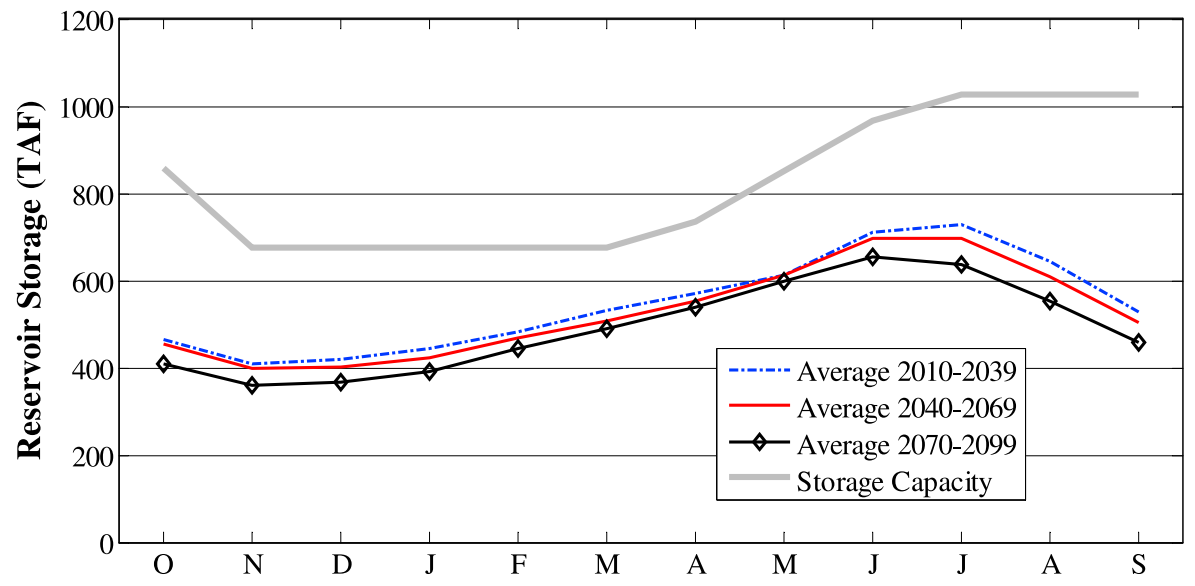

Figure 7. Average reservoir storage for all climate change projections. TAF, thousand acre feet.

inflows and the incentive to maximize storage. Increases in groundwater pumping reduce groundwater levels. Figure 8 shows the average annual change in groundwater levels across climate change projections. There is a large uncertainty in aquifer head across projections. The historical aquifer levels in this basin clearly show the effects of the two droughts, on top of the overall declining trend owing to aquifer overdrafts in the last 30 years of the 20th century: the 1976-1977 and 1988-1992 droughts. There is still much uncertainty in the results, with some projections showing increased groundwater levels (making them almost comparable to pre-1988 conditions), but other scenarios reduce aquifer head almost 150 feet $(45.7 \mathrm{~m})$. On average, groundwater levels decline into the 21 st century.

[34] A summary of these results is presented in Tables $2 \mathrm{a}$ and $2 \mathrm{~b}$. Shown in Tables $2 \mathrm{a}$ and $2 \mathrm{~b}$ are averages over all projections for three time periods into the 21 st century, as well as the benefits and costs from water use in the basin. We also provide the average ratio of values in the middle and later 21 st century to those in early 21 st century (except for the aquifer head, where it makes more sense to show the actual head difference from the early 21 st century). Reduced annual inflows reduce reservoir releases. However, reduced water use to generate hydropower and irrigate farms is notable by the end of the century; although less water is stored in the reservoirs, average spills increase over time. The increase in spills, the disproportionate decrease in water diversions (and increase in pumping), compounds the effect of a less convenient hydrology on system operations. These effects reduce the benefits from water use. From an energy perspective the basin moves from a surplus to a deficit condition, but only in value, not absolute energy; pumping costs rise to exceed the value of hydropower revenues but only because the price for pumping in per megawatt hour exceeds the value from generation by about a factor of 2; absolute GWh remains higher from hydrogeneration. Summarizing these last points is that the increased temperature from climate change decreases the amount of water when we need it and increases it when we do not. In the next appli-

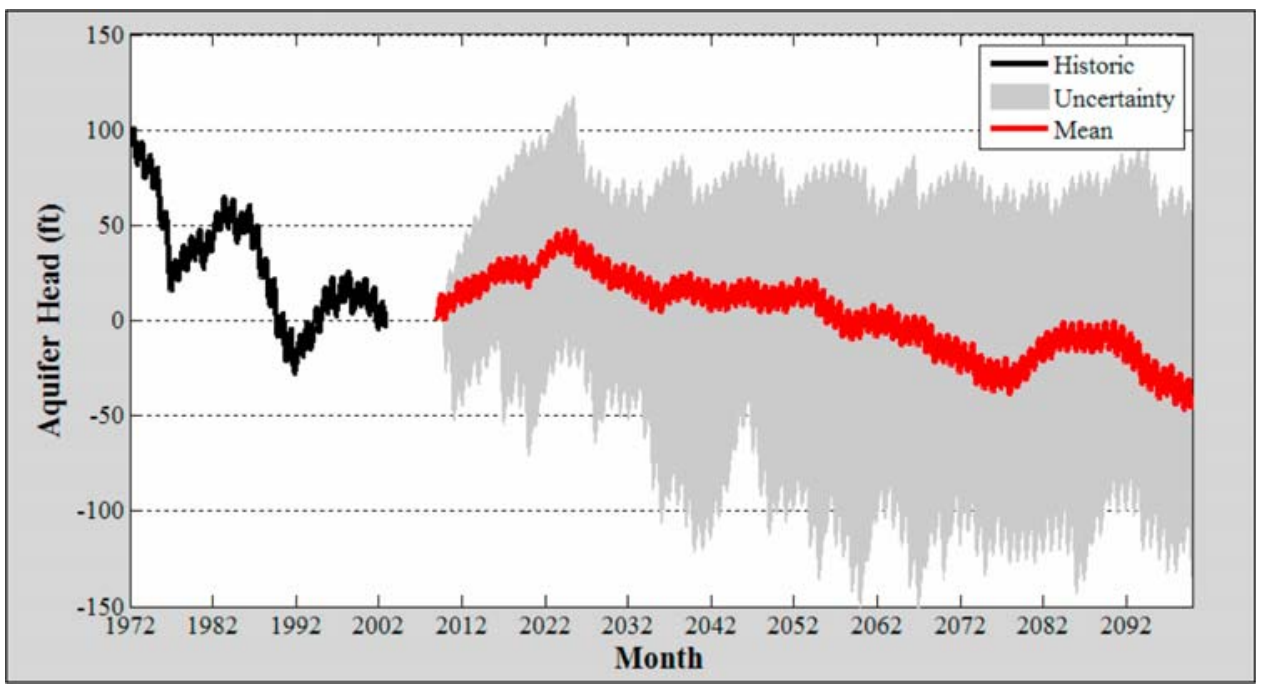

Figure 8. Groundwater levels under climate change projections in Merced River basin. 
Table 2a. Summary of Results Under Climate Change Hydrologic Conditions: Operations ${ }^{\mathrm{a}}$

\begin{tabular}{|c|c|c|c|c|c|c|c|}
\hline Period $^{\mathrm{b}}$ & $\begin{array}{c}\text { Annual } \\
\text { Inflows (TAF/yr) }\end{array}$ & $\begin{array}{l}\text { Annual Release } \\
\text { Turbine (TAF/yr) }\end{array}$ & $\begin{array}{c}\text { Annual } \\
\text { Spill (TAF/yr) }\end{array}$ & $\begin{array}{c}\text { Annual } \\
\text { Diversion (TAF/yr) }\end{array}$ & $\begin{array}{c}\text { Annual } \\
\text { Pumping (TAF/yr) }\end{array}$ & $\begin{array}{c}\text { EoS } \\
\text { Storage (TAF) }\end{array}$ & $\begin{array}{l}\text { EoS Head } \\
\quad \text { (feet) }\end{array}$ \\
\hline Average 2011-2040 & 1111 & 980 & 100 & 570 & 306 & 529 & 17 \\
\hline Bounds & $726 / 1507$ & $696 / 1279$ & $20 / 253$ & $455 / 661$ & $256 / 389$ & $389 / 658$ & $-27 / 56$ \\
\hline Average $2041-2070$ & $1025(92 \%)$ & $901(92 \%)$ & $118(118 \%)$ & $518(91 \%)$ & $339(111 \%)$ & $504(95 \%)$ & $-1(-18)$ \\
\hline Bounds & $497 / 1955$ & $483 / 1402$ & $1 / 527$ & $309 / 661$ & $269 / 432$ & $264 / 728$ & $-96 / 62$ \\
\hline Average $2071-2100$ & $1009(91 \%)$ & $820(84 \%)$ & $146(147 \%)$ & $450(79 \%)$ & $364(119 \%)$ & $459(87 \%)$ & $-28(-45)$ \\
\hline Bounds & $485 / 2177$ & $452 / 1268$ & $281 / 650$ & $4 / 754$ & $262 / 448$ & $228 / 723$ & $-108 / 59$ \\
\hline
\end{tabular}

${ }^{\mathrm{a}}$ Abbreviations are as follows: EoS; end of September; TAF, thousand acre feet.

${ }^{\mathrm{b}}$ For the average, the value in parentheses is the percent change over the average condition for the first time period (2011-2040). For bounds, the first number is the minimum and the second number is the maximum.

cation we explore some strategies to overcome this new hydrologic inconvenience.

\section{Second Application: Adaptations to Climate Change}

\subsection{Adaptation Strategies}

[35] The base case results presented in section 5 showed, as expected, that reduced water availability reduces benefits in the MRB. However, reduced benefits could be less if changes in inflow timing and flood events were better handled. The SSDP/nonlinear programming (NLP) approach allows some adaptive management by acknowledging the changing hydrologic conditions from climate change. Associated with this idea of adaptive management, using better short- and medium-range forecasts (from broad-scale climate indicators such as El Niño-Southern Oscillation and Pacific Decadal Oscillation or downscaled GCM climatic data) should help reduce inconveniences of new hydrologic conditions [Georgakakos et al., 2005]. However, the adaptation potential is limited by physical, institutional, and regulatory constraints. Extending the results of the base case, we modified some constraints to explore potential long-term adaptations to reduce the effects of changing hydrology. Three types of adaptation strategies are explored: infrastructure changes, systems reoperation, and institutional changes.

[36] One adaptation option is explored in each category: an increase in reservoir storage capacity, a change in flood control rules, and employing conjunctive use to operate the MRB. First, interannual variability could increase with climate change [Timmermann et al., 1999]. Increasing reservoir storage capacity could mitigate some increased variability, allowing storage of more water in surplus years or seasons for use in dry years or seasons. However, a change in storage capacity is not useful for the driest scenarios where any extra storage capacity remains mostly underused. Second, a proposed change to the flood control rule is based on the idea that the effects of earlier timing of inflows could be partly mitigated by earlier timing of flood control constraints. With earlier flood control regulation the effects of losing water that could be stored in early spring months could diminish [Van Rheenen et al., 2004; Lee et al., 2006]. A simple change could be to start refilling 1 or 2 months earlier but increasing the flood control space in winter to accommodate the larger expected floods. The suggested strategies maintain the same flood storage capacity but modify its timing to accommodate changes in streamflow conditions (see Figure 9). It is unclear how robust this strategy would be across scenarios. For very dry scenarios this new flood control rule should not affect results greatly because the maximum allowable storage is seldom reached. For very wet scenarios, changing the flood control should not affect results either because water supply is constantly met and hydropower turbines are running close to capacity without much added benefit from relaxing the storage constraint in spring months. Finally, new groundwater usage institutional arrangements (with necessary infrastructure such as spreading basins) allows an effective conjunctive use scheme in the basin to permit more efficient timing of both reservoir and aquifer operations and to allow systematic artificial recharge to help mitigate impacts of a more variable hydrology. Other studies of climate warming in California also support this strategy [Tanaka et al., 2006; Medellin-Azuara et al., 2008].

[37] We begin by presenting adaptations for changing flood rules and increasing the size of Lake McClure's reservoir. The results of these two strategies are compared considering average annual benefits for 30 years starting when the change is introduced. We consider two changes in

Table 2b. Summary of Results Under Climate Change Hydrologic Conditions: Costs and Benefits

\begin{tabular}{|c|c|c|c|c|c|c|}
\hline Period $^{\mathrm{a}}$ & $\begin{array}{l}\text { Hydropower } \\
\text { (GWh/yr) }\end{array}$ & $\begin{array}{l}\text { Hydropower } \\
\text { (Millions of } \\
\text { Dollars/yr) }\end{array}$ & $\begin{array}{l}\text { Pumping Costs } \\
\text { (GWh/yr) }\end{array}$ & $\begin{array}{l}\text { Pumping Costs } \\
\text { (Millions of } \\
\text { Dollars/yr) }\end{array}$ & $\begin{array}{l}\text { Ag Benefits } \\
\text { (Millions of } \\
\text { Dollars/yr) }\end{array}$ & $\begin{array}{l}\text { All Benefits } \\
\text { (Millions of } \\
\text { Dollars/yr) }\end{array}$ \\
\hline Average 2011-2040 & 302.8 & 8.4 & & 4.8 & 24.2 & 27.8 \\
\hline Bounds & $194.7 / 414.4$ & $5.6 / 11.4$ & $79.852 .9 / 123.7$ & $3.2 / 7.4$ & $20.9 / 25.7$ & $22.5 / 32.5$ \\
\hline Average $2041-2070$ & $274(90 \%)$ & $7.6(90 \%)$ & $97.2(122 \%)$ & $5.8(122 \%)$ & $24.1(100 \%)$ & $25.9(93 \%)$ \\
\hline Bounds & $110.5 / 466.7$ & $3.2 / 12.5$ & $53.4 / 175$ & $3.2 / 10.5$ & $22.5 / 25.5$ & $15.5 / 33.3$ \\
\hline Average 2071-2100 & $242.5(80 \%)$ & $6.7(79 \%)$ & $117.5(147 \%)$ & $7.1(147 \%)$ & $23.5(97 \%)$ & $23.1(83 \%)$ \\
\hline Bounds & $97 / 413.2$ & $2.9 / 10.9$ & $52.4 / 183.7$ & $3.1 / 11$ & $20 / 24.9$ & $14.5 / 31.2$ \\
\hline
\end{tabular}

${ }^{\mathrm{a}}$ For the average, the value in parentheses is the percent change over the average condition for the first time period (2011-2040). For bounds, the first number is the minimum and the second number is the maximum. 


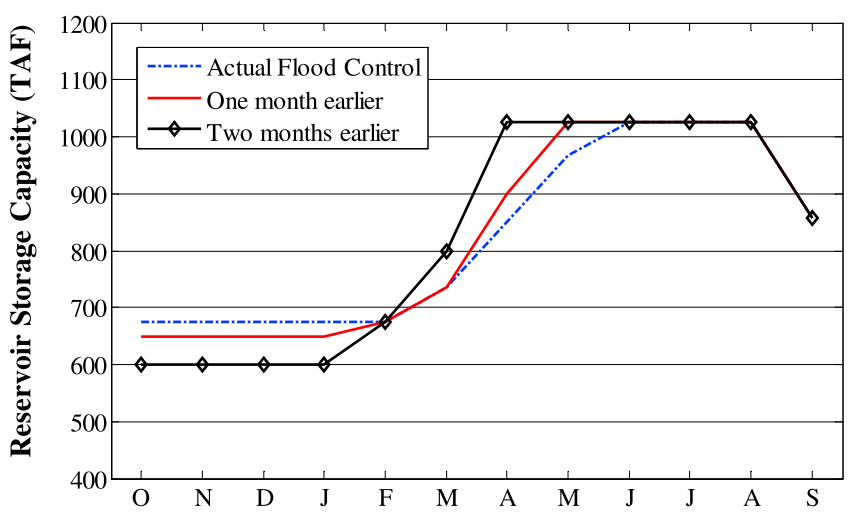

Figure 9. Actual and suggested flood control rules for the operations of Lake McClure. TAF, thousand acre feet.

the flood control rule and one increase in storage capacity by $123 \mathrm{MCM}$ (100 TAF). We consider three times for introducing the strategy. The combination gives a set of 15 alternative strategies. Figure 10 summarizes the results for a subset of these strategies focusing only on adopting strategies early and late in the 21 st century. For each strategy we present the average change in net present value for the 30 years over all projections, and the minimum and maximum change.

[38] Without increasing storage capacity, changing flood control rules improves average annual benefits less than $1 \%$ (about \$250,000/yr), with some projections having reduced benefits. Average improvement is greater with implementation later in the 21 st century and greater for the earlier "two months" extension of the flood control rule. However, for the same two cases the dispersion of results across scenarios is greater with a more negative minimum change than in the previous case. For strategies with an increase in storage capacity we see overall annual benefits increase, with all projections showing a positive improvement (except the case of adopting a 2 months earlier flood control rule in year 2010). The average improvement from increasing storage (without a change in the flood control rule) introduced in 2010 is around $\$ 5.4$ million $/ \mathrm{yr}$ or $\$ 66,000 / \mathrm{m}^{3} / \mathrm{yr}(\$ 54 / \mathrm{AF} / \mathrm{yr})$ of extra capacity (and $\$ 910,000 / \mathrm{m}^{3} / \mathrm{yr}$, or $\$ 730 / \mathrm{AF} / \mathrm{yr}$ if introduced in 2070). However, unlike the first cases, these improvements have to be compared with costs of increasing reservoir size. Average benefits improve if we delay adoption of this improvement. This could imply some synergy in benefits from increasing storage and changing flood control rules with the projected hydrology for late 21 st century.

[39] Relaxing flood regulations in early spring months reduces both spills and releases through turbines in these months, which are less valuable for both hydropower production and farm irrigation. This extra water is stored in the reservoir, increasing the head (not shown), increasing late spring and summer releases for hydropower and irrigation, and reducing groundwater pumping. This happens for most projections. However, for some projections the strategy reduces benefits. These reduced benefits result from increased spills in winter months (and the cascade of effects that follow) owing to a worse handling of floods in winter with the new deeper flood control pool of this adaptation strategy. The model has a simple approach to simulate winter operations with simple rules to keep reservoirs as full as possible (i.e., there is no optimization in this part of the algorithm but pure simulation instead). Real winter reservoir operations are more sophisticated than these simple rules, and flood control space is sometimes used during especially high-flood events. In real-time operation under a given climate projection some of this bad handling of floods might be better than predicted here so we would expect an improvement of benefits. It is hard to test this idea with this simple and coarse (in time resolution) winter model. On the basis of these results, there seems to be no win-win adaptation strategy from operation of New Exchequer Dam (at

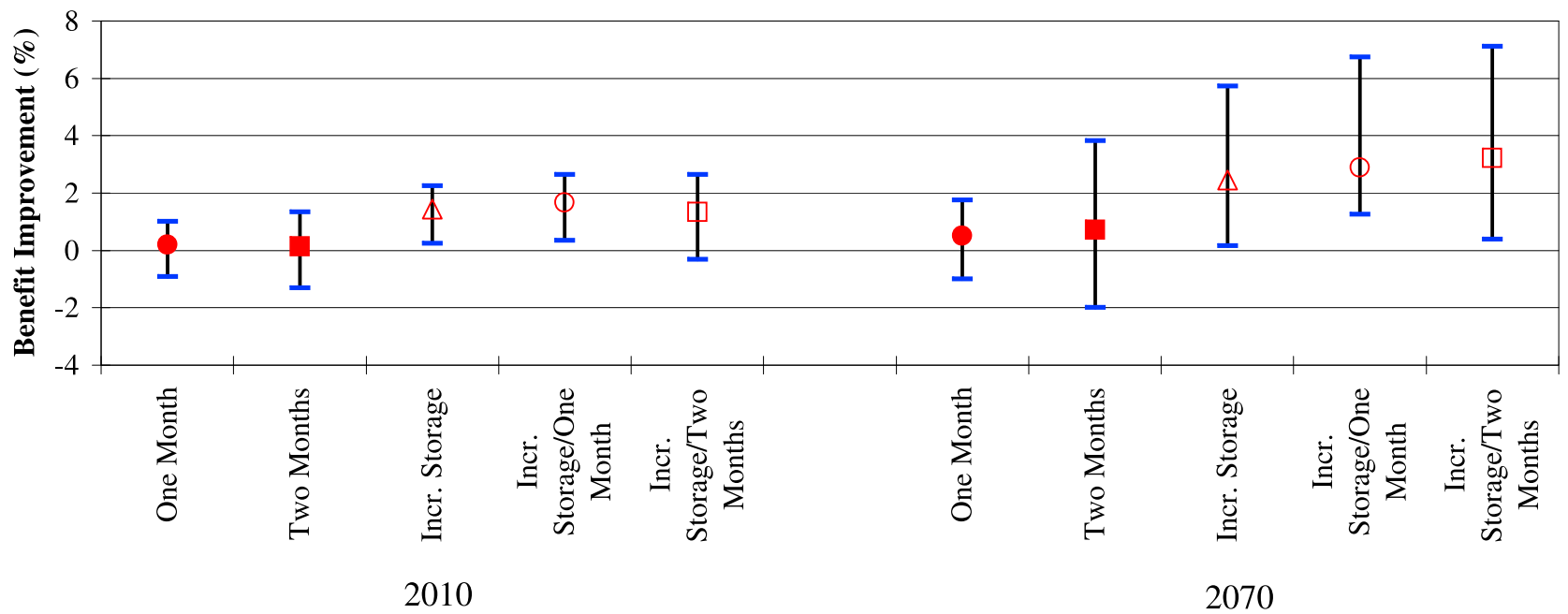

Strategy/Adoption Year

Figure 10. Comparison between base case and adaptation scenarios. Presented are the results for strategies with and without change in storage. For each adaptation scenario we present the average result across climate change projection and also the minimum and maximum change. 
Table 3a. Summary of Average and Extreme Results With Conjunctive Use: Operations ${ }^{\mathrm{a}}$

\begin{tabular}{|c|c|c|c|c|c|c|c|}
\hline Period $^{\mathrm{b}}$ & $\begin{array}{l}\text { Annual } \\
\text { Inflows } \\
\text { (TAF/yr) }\end{array}$ & $\begin{array}{c}\text { Annual Release } \\
\text { Turbine } \\
\text { (TAF/yr) }\end{array}$ & $\begin{array}{c}\text { Annual } \\
\text { Spill } \\
\text { (TAF/yr) }\end{array}$ & $\begin{array}{l}\text { Annual } \\
\text { Diversion } \\
\text { (TAF/yr) }\end{array}$ & $\begin{array}{l}\text { Annual } \\
\text { Pumping } \\
\text { (TAF/yr) }\end{array}$ & $\begin{array}{l}\text { EoS Storage } \\
\text { (TAF) }\end{array}$ & $\begin{array}{l}\text { EoS Head } \\
\text { (feet) }\end{array}$ \\
\hline Average 2011-2040 & 1111 & $982(0.2 \%)$ & $100(0.4 \%)$ & $663(16.3 \%)$ & $285(-7 \%)$ & $491(-7.3 \%)$ & $32(15)$ \\
\hline Bounds & $726 / 1507$ & $699 / 1269$ & $20 / 263$ & $492 / 824$ & $250 / 346$ & $350 / 620$ & $-11 / 60$ \\
\hline Average 2041-2070 & 1025 & $905(0.4 \%)$ & $114(-2.9 \%)$ & $618(19.5 \%)$ & $302(-10.9 \%)$ & $457(-9.3 \%) 210 / 686$ & $32(33)$ \\
\hline Bounds & $497 / 1955$ & $494 / 1417$ & $2 / 512$ & $336 / 892$ & $221 / 375$ & & $-46 / 103$ \\
\hline Average 2071-2100 & 1009 & $822(0.3 \%)$ & $145(-0.9 \%)$ & $560(24.5 \%)$ & $319(-12.2 \%)$ & $418(-8.7 \%)$ & $15(42)$ \\
\hline Bounds & $485 / 2177$ & $460 / 1272$ & $5 / 752$ & $302 / 814$ & 219/396 & $166 / 682$ & $-58 / 100$ \\
\hline
\end{tabular}

${ }^{a}$ Abbreviations are as follows: EoS; end of September; TAF, thousand acre feet.

${ }^{\mathrm{b}}$ For the average, the value in parentheses is the percent change over the average condition for the first time period (2011-2040). For bounds, the first number is the minimum and the second number is the maximum.

least without the cost data needed to compare with improvements for increased storage).

\subsection{Conjunctive Use Framework as an Adaptation Option}

[40] Although conjunctive use of ground and surface water has been analyzed previously [Tanaka et al., 2006] as a statewide climate adaptation strategy, there has not been a detailed local study on the specific role of conjunctive use in a single basin with a new hydrologic environment. Several obstacles need to be overcome to implement effective conjunctive use [Coe, 1990]. However, conjunctive use could allow more effective timing of reservoir releases and groundwater pumping considering varying energy prices within a year. There are also benefits from artificially recharging an aquifer when water availability allows [Vicuna, 2007].

[41] The SSDP/NLP model used previously is expanded here to include a new state variable (aquifer head) and a new decision variable (groundwater pumping). Now, instead of a reservoir operator making decisions about releases and farmers later making use of this water and pumping groundwater, both reservoir releases and groundwater pumping levels are decided considering all present and future costs and benefits for the basin. This helps mitigate some effects of changes in hydrograph timing and increased hydrologic variability.

[42] Tables $3 \mathrm{a}$ and $3 \mathrm{~b}$ contain a summary of the system variables for the conjunctive use case (and average percent changes over the base case) for the three periods in the 21 st century. Figure 11 presents average monthly operations for the four decision variables. Conclusions from these results include:
[43] 1. A conjunctive use framework for optimizing operations in MRB with climate change increases net benefits for all projections.

[44] 2. The average increase in benefits is around $2 \%$ which is comparable with the results from increased storage capacity in section 6.1.

[45] 3. Increased benefits come from slightly greater hydropower revenues and substantially reduced pumping costs.

[46] 4. River diversions increase in early spring when "unnecessary" water is used to artificially recharge the aquifer. This artificial recharge and reduced groundwater pumping increase groundwater levels which stay mostly at present levels. Figure 12 compares aquifer levels (including the uncertainty) for both scenarios. Coordinated operation of the reservoir and aquifer permit more efficient timing of reservoir releases and groundwater pumping which increases the value of hydropower generated. Generation occurs later in the year with conjunctive use because the availability of recharged water allows the operators to generate more in the late summer and come into the new water year with less water in the reservoir.

[47] 5. Previous work for the same basin with historical hydrologic conditions [Vicuna, 2007] shows that the benefits of conjunctive use with artificial recharge were about a $0.5 \%$ increase. In this case the average increase in benefits is more than $2 \%$, suggesting that changed hydrologic conditions increase incentives for conjunctive use.

[48] 6. In that study, incorporating part of the irrigated land that today does not receive surface supplies from the Merced irrigation district further increases the benefits of conjunctive use. It is expected that this should also be the case with climate change hydrologic conditions; that is, if the land outside the MID territory was also supplied by

Table 3b. Average and Extreme Results With Conjunctive Use: Costs and Benefits ${ }^{\mathrm{a}}$

\begin{tabular}{|c|c|c|c|c|c|c|}
\hline Period $^{\mathrm{b}}$ & $\begin{array}{l}\text { Hydropower } \\
\text { (GWh/yr) }\end{array}$ & $\begin{array}{l}\text { Hydropower } \\
\text { (Millions of } \\
\text { Dollars/yr) }\end{array}$ & $\begin{array}{l}\text { Pumping Costs } \\
\text { (GWh/yr) }\end{array}$ & $\begin{array}{l}\text { Pumping Costs } \\
\text { (Millions of } \\
\text { Dollars/yr) }\end{array}$ & $\begin{array}{l}\text { Ag Benefits } \\
\text { (Millions of } \\
\text { Dollars/yr) }\end{array}$ & $\begin{array}{l}\text { All Benefits } \\
\text { (Millions of } \\
\text { Dollars/yr) }\end{array}$ \\
\hline Average 2011-2040 & $302.1(-0.2 \%)$ & $8.7(2.7 \%)$ & $68.3(-14.4 \%)$ & $4.1(-14.4 \%)$ & $23.6(-2.5 \%)$ & $28.1(1.1 \%)$ \\
\hline Bounds & $194.6 / 410$ & $5.8 / 11.6$ & $50.5 / 100$ & $3 / 6$ & $20.6 / 25$ & $22.5 / 32.8$ \\
\hline Average 2041-2070 & $274(0 \%)$ & $7.8(2.8 \%)$ & $73.6(-24.3 \%)$ & $4.4(-24.3 \%)$ & $23.1(-4.3 \%)$ & $26.5(2.2 \%)$ \\
\hline Bounds & $112.1 / 471.5$ & $3.4 / 12.8$ & $31.8 / 127.6$ & $1.9 / 7.7$ & $20.2 / 24.5$ & $16 / 34.6$ \\
\hline Average 2071-2100 & $243.6(0.5 \%)$ & $6.9(3.2 \%)$ & $86(-26.9 \%)$ & $5.2(-26.9 \%)$ & $22(-6.2 \%)$ & $23.8(2.8 \%)$ \\
\hline Bounds & $96.6 / 417.1$ & $3 / 11.1$ & $32 / 140.2$ & $1.9 / 8.4$ & $19.6 / 23.8$ & $14.5 / 30.9$ \\
\hline
\end{tabular}

${ }^{\text {a }}$ The cumulative anomalies are defined through $D_{1, i}=A_{1, i}$ and $D_{t+1, i}=D_{t, i}+\left(A_{t, i}-\bar{I}\right)$, where $\bar{I}$ corresponds to the average historic inflows, $A_{t, i}$ is the series $i$ inflow at time $t$, and $D_{t, i}$ is the cumulative anomaly of series $i$ by time $t$.

${ }^{\mathrm{b}}$ For the average, the value in parentheses is the percent change over the average condition for the first time period (2011-2040). For bounds, the first number is the minimum and the second number is the maximum. 

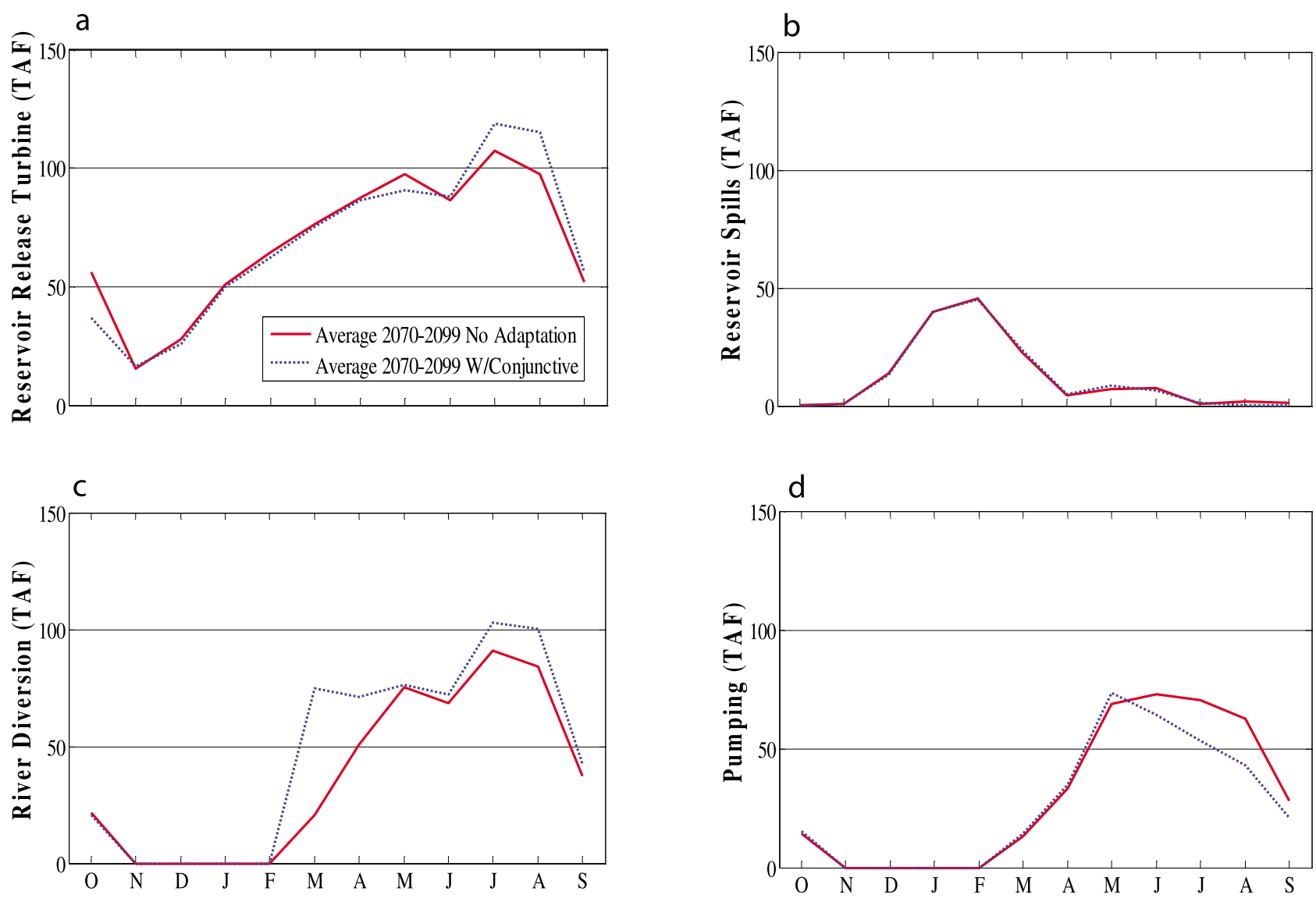

Figure 11. Average system operations for all climate change projections under conjunctive use scheme: (a) reservoir releases through turbines, (b) spills, (c) river diversion, and (d) groundwater pumping. TAF, thousand acre feet.

surface water released from Lake McClure, there would be an increase in annual benefits from conjunctive use.

\section{Third Application: Benefits of a New Reservoir in the Merced River Basin}

[49] This third application explores the case of a basin without surface water storage and hence an agriculture sector that relies on highly variable streamflow for diversion and groundwater extractions as the only source of water to irrigate their lands. Farmers in this basin consider constructing a reservoir to reduce variability in water supplies, storing water in wet years for use in dry ones. A reservoir also helps move water from early spring (when it becomes available in the Merced River) to late spring and summer for irrigation.

[50] The farmers in this hypothetical situation need to select the optimal size of the reservoir. Finding an optimal reservoir size is one of the oldest problems in water resources engineering [Rippl, 1883; Klemes, 1987]. Usually, historical hydrologic conditions are used to estimate the benefits of various reservoir sizes, and then these benefits are compared with construction costs to determine the optimal size. This approach assumes that the hydrology is stationary, and so making decisions on the basis of past conditions should suffice. However, hydrologic conditions are expected to change. The magnitude and direction of these changes are unclear in some cases, but there will be a change. It makes sense to explore the optimal size of a reservoir on the basis of projections of hydrologic conditions rather than the historical case.

[51] We explore such a situation by studying the benefits of a hypothetical "new" reservoir on the Merced River. For this, we solved different SDDP problems (different scenarios $\psi$ using the notation introduced in section 3 ), each one with a different reservoir size, from no reservoir to a maximum of $1760 \mathrm{MCM}$ (1425 TAF) (current storage capacity is $1265 \mathrm{MCM}$, or $1025 \mathrm{TAF}$ ). For each reservoir size we obtain optimal operations for a period of 30 years (starting in 2010) using our set of climate projections. The discounted present (year 2010) value for these streams of benefits is calculated using a discount rate of 5\%. Figure 13 shows the benefits of different reservoir sizes for the range of climate scenarios. Even without once through use of the water.

[52] We then estimated the hypothetical construction costs for each reservoir capacity using the following relationship between storage and cost: Cost $=a S^{b}$. Recognizing some economies of scale on building a reservoir and costs estimated for building reservoirs in locations close to the MRB, we use a value of 0.7 for parameter $b$ and a value of 20 for parameter $a$.

[53] Finally, we estimated marginal costs and marginal benefits that can be derived from both the present discounted value of benefits and construction costs explained above. Figure 14 compares these two figures for a range of reservoir sizes. From Figure 14, for small reservoir sizes, 


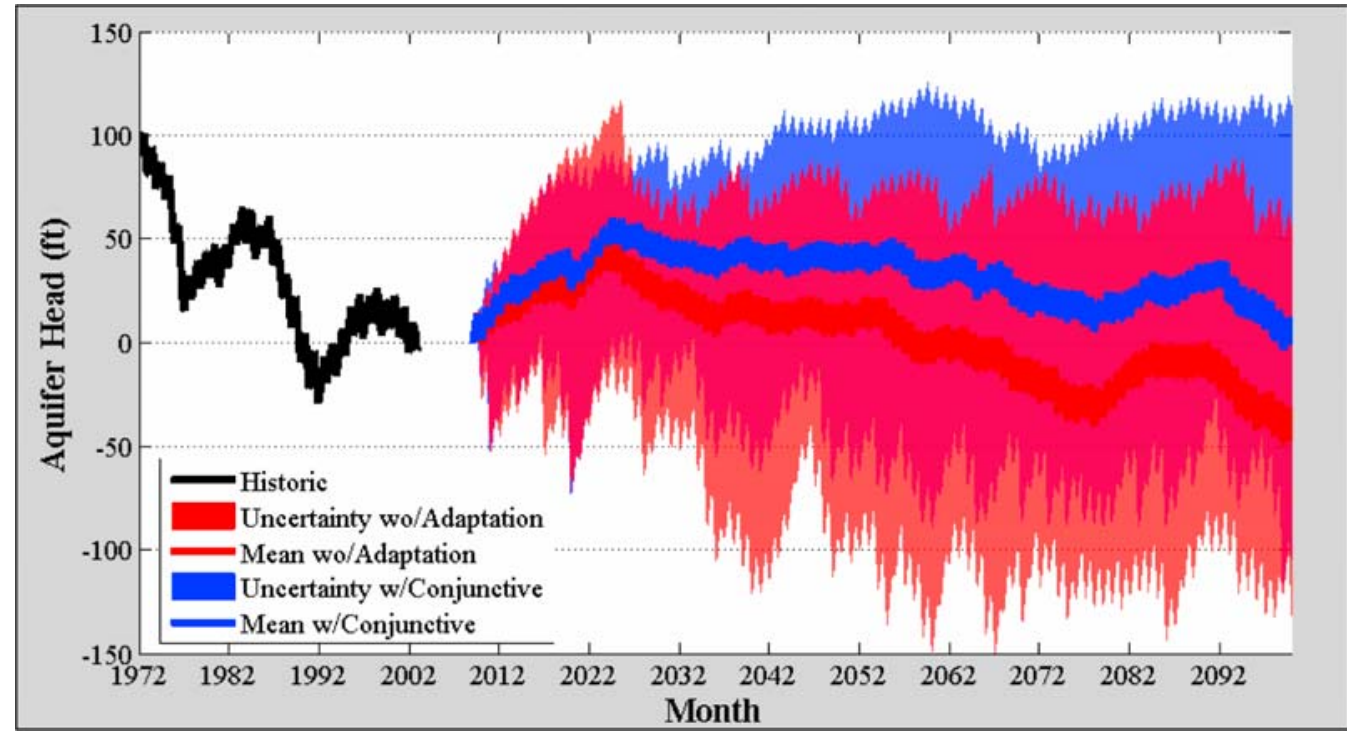

Figure 12. Groundwater levels under climate change projections for the base and conjunctive use scenarios.

marginal benefits exceed marginal costs. It is also shown that both marginal benefits and marginal costs decrease with higher storage and that marginal benefits decrease more quickly [Hazen, 1914]. Each climate scenario has an optimal reservoir size. The difference between these sizes is not large in this hypothetical example. If we consider either the driest or wettest projections, the answer varies from roughly 940 to $1020 \mathrm{MCM}$ (760 to $825 \mathrm{TAF}$ ) from the driest to the wettest climate scenario. If the future turns out to be drier than current conditions and you have a reservoir that is "too" large, it would be hard to refill it, and hence not all of its potential would be used. If the future is wet enough (or interannual variability is high) and costs low enough, it makes sense to build a large reservoir. If the reservoir is built anticipating a range of potential climates, its optimal size, using an expected value criterion, is slightly less than $990 \mathrm{MCM}(800 \mathrm{TAF})$.

[54] The analysis presented could be further refined if climate projections were weighted differently depending on their perceived skill in simulating historical climate conditions [Brekke et al., 2009]. However, consistent with prior work [Dettinger, 2005], Brekke et al. [2009] found that weighting climate model output on the basis of skill in reproducing historical climate statistics does not have a substantial effect on projection results, and even the determination of "better" models depend on the choice of metric. More recent work [Pierce et al., 2009] arrived at similar conclusions and advocates using ensembles of GCMs for

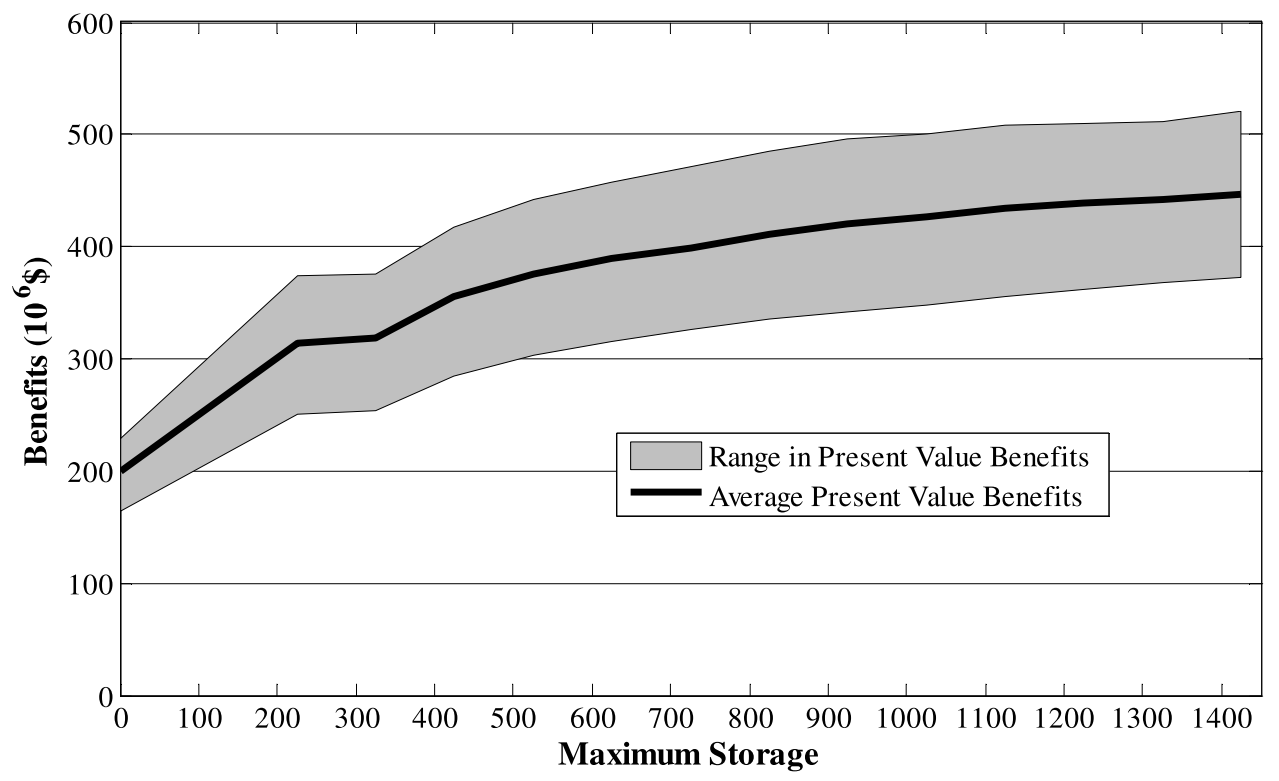

Figure 13. Present discounted benefits for different reservoir size scenarios. 


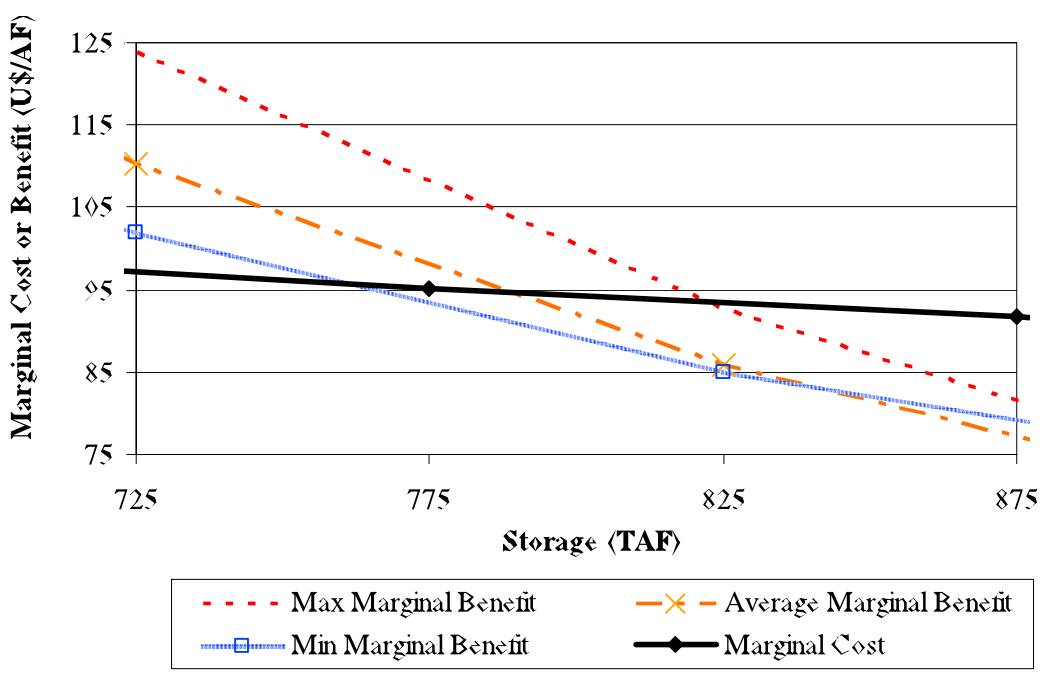

Figure 14. Comparison between marginal benefits and marginal costs of building different reservoir sizes in the Merced River basin. TAF, thousand acre feet.

regional impacts studies. Thus we include a large ensemble of results and look for robust alternatives that do well under many or all models, rather than focusing on a small set of models determined to be more skillful.

\section{Conclusions}

[55] An optimization algorithm was developed to derive water resource system operating rules for nonstationary and uncertain hydrologic conditions. This algorithm combines an annual SSDP model with an embedded monthly nonlinear deterministic model. This SSDP/NLP was applied to three case studies of climate change and water management for the Merced River basin in the east San Joaquin Valley of California. A first case study estimated impacts of climate change, allowing some adaptation to the changing climate conditions within the constraints of today's system configuration. The average results showed a decline in economic benefits for water use in the basin. However, the results also showed great uncertainty with increased benefits for some climate projections. The reduction in benefits arises from reductions in overall water availability compounded by the hydrologic timing effects of increased temperatures. Groundwater levels also decrease on average in the future, with some projections having increased aquifer levels.

[56] A second set of case studies incorporate long-term adaptation strategies for climate change. The adaptation strategies include: changes in the flood control rule, enlarging the dam regulating Merced River streamflow, and conjunctive use of ground and surface water. Averaging over all climate projections and periods, all adaptation strategies are beneficial. However, changing reservoir flood control rules produces worse results for some projections. Increasing the reservoir size increases average benefits, but the net benefits of expanding the reservoir can be negative, depending on construction costs. The last adaptation option considered, conjunctive use, seems to be the only "robust" strategy that presents benefits for all climate change projections by effectively mitigating the negative consequences of modified hydrologic conditions. The benefits of con- junctive use also seem to be larger than those expected under current hydrologic conditions.

[57] A final application of the method developed considered a hypothetical example of one of the oldest applications in the water resources engineering field, establishing the optimal size of a reservoir. This example was applied to the same Merced River basin assuming no existing reservoir. Assumptions were made about the construction costs and discount rates to bring annual benefits to a present value. The example shows the value of including uncertainty about future hydrologic conditions in the decision about building new reservoirs or, for that matter, planning for any other water resources infrastructure.

[58] We are unlikely to know the statistical properties of nonstationary hydrologies [Klemes, 2000]. Methods such as those developed here might help employ what we do know for operational, planning, and policy studies.

\section{Appendix A: Transition Probabilities}

[59] Appendix A explains the procedure used to estimate transition probabilities between different climate change projections of hydrologic conditions to be used in the SSDP model. The objective was to create transition probabilities that evolve over time and capture the likelihood, as climate change progresses in the future, of switching from one trajectory (i.e., a GCM run forced by either the higher A2 or lower B1 pathway of projected atmospheric greenhouse gas concentrations) to another. For the next few decades the trajectories are similar, diverging more dramatically later in the 21st century [Cayan et al., 2008; Hayhoe et al., 2004], so the probability of being on any one trajectory is almost independent and identical for the first few decades of the 21 st century.

[60] This is demonstrated in Figures A1 and A2, where we show two examples of the transition probabilities for the applications provided in the paper for the Merced River basin. Figure A1 shows the transition probabilities for 2030, and Figure A2 shows the transition probabilities for 2080. By comparing the transitions for the first two rows (models Centre National Recherche Meteorologique (CNRM) and 


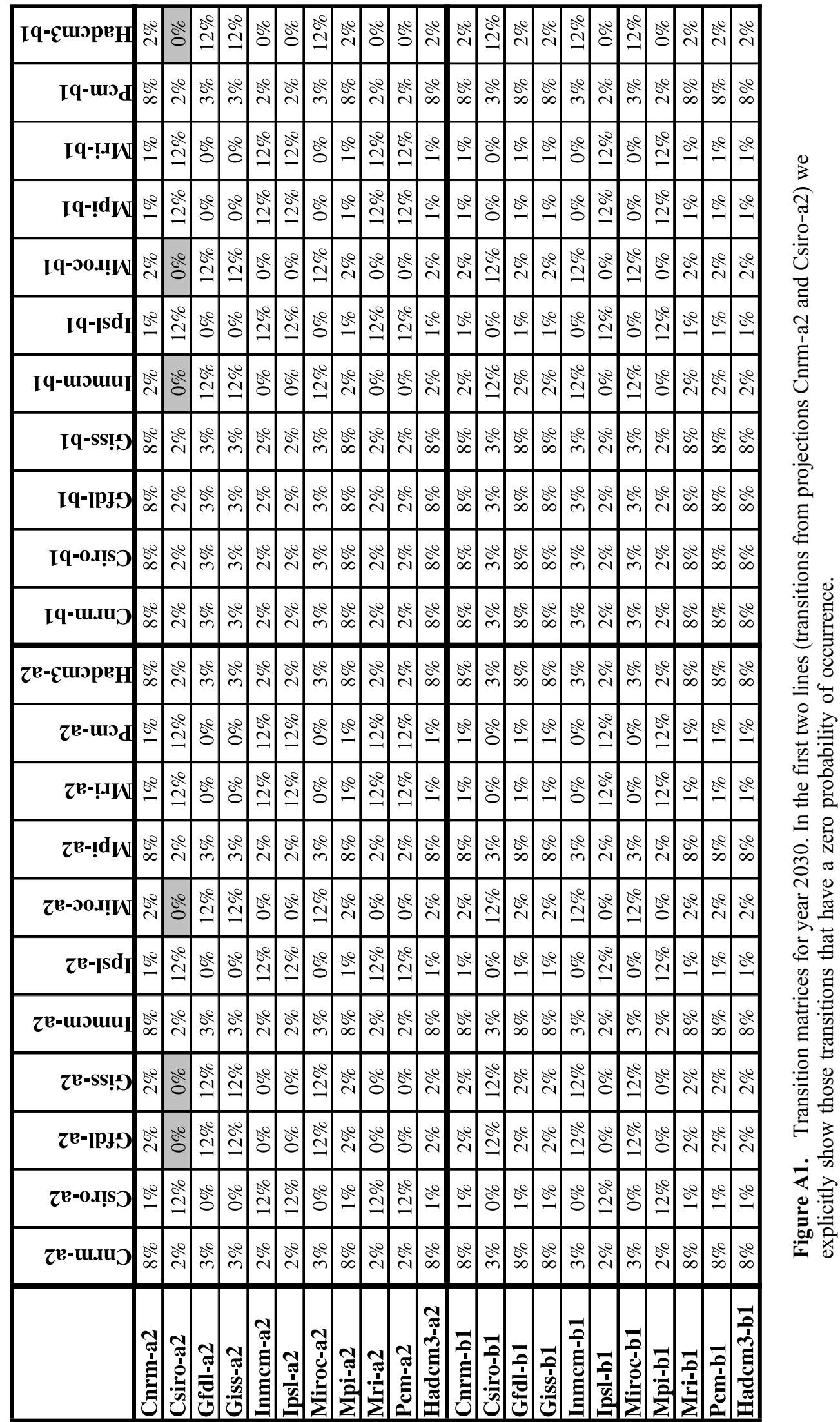




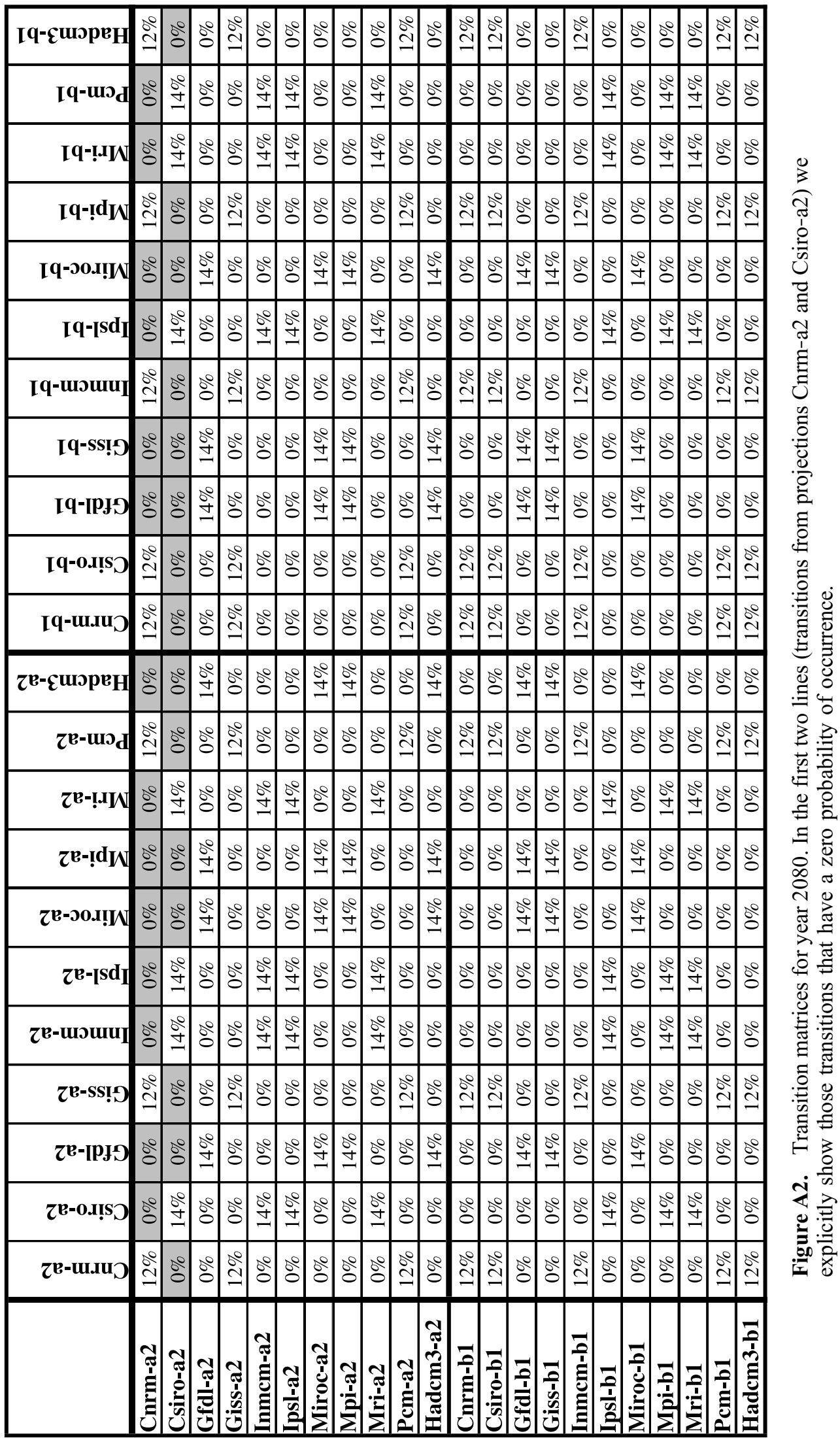


Commonwealth Scientific and Industrial Research Organisation (CSIRO), both with the A2 greenhouse gas emission scenario), it is clear how earlier in the 21 st century there is a greater number of projections to which transitions can occur, whereas later in the century, transitions happen only between very similar projections. Also, comparing two very different projections, namely the higher-sensitivity HadCM3 with the higher A2 emissions and the lower-sensitivity PCM with lower B1 emissions, the transition probability between the two is $8 \%$ for 2030 and $0 \%$ for 2080 , demonstrating the evolving probabilities through the 21 st century toward more limited transitions.

[61] The transition probability determination method starts by considering the time series of annual hydrologic conditions (inflows to reservoir) for the different climate projections. Call this $A_{t, i}$, where $t$ is the year (e.g., $t=1950$ 2100) and $i$ represents the different projections' ensemble (e g., $i_{1}=$ PCMB1; $i=1: m$ ). For these time series we calculate the cumulative anomalies, where $D_{t, i}$ is a hydrologic measure that allows us to represent the necessary hydrologic deviation to distinguish among different future climate trajectories. Then for each year $t$ the distribution of anomalies is calculated for a set of $n$ different percentile values, $D_{t}^{p_{h}}$ (where $p_{h}$ is a percentile value; e.g., $80 \%, p_{h} \in P_{h}, h=1: n$ ). The number $n$ of percentile values included in the set $P_{h}$ is a critical parameter in determining the transition probability matrices. After an exploratory analysis of the hydrologic conditions expected by each decision-making process in the SSDP algorithm on the case study presented, we decided that $n=3$ gave us the best result. After calculating $D_{t}^{p_{h}}$, we calculate the empirical frequency of occurrence of transitions between any of these possible percentile values as explained below.

[62] For every $2010<t_{c c}<2100$, apply the following steps.

Step 1. Create null $n \times n$ matrix $\mathbf{P}_{F}^{t_{c c}}$ of frequency of hits for different $p_{h}$.

Step 2. For every member of the sequence $i$

Step 3. For every year $t_{c c}-41<t<t_{c c}-1$ (arbitrarily looking at the last 40 years to determine the transition probabilities at any given point in time).

3a. First, determine $p_{h}$ group for year $t$ and sequence $i$ by selecting the appropriate index from $P_{h}$ and $D_{t}^{p_{h}}$, say $p_{*}$.

$3 \mathrm{~b}$. Determine the $p_{h}$ group for year $t+1$ and sequence $i$ by selecting the appropriate index from $P_{h}$ and $D_{t}^{p_{h}}$, say $p_{* *}$.

3c. Then $\mathbf{P}_{F}^{t_{c c}}(*, * *)$ (frequency count of moving from index $p_{*}$ to index $\left.p_{* *}\right)=\mathbf{P}_{F}^{t_{c c}}(*, * *)+1$.

End (move to next year)

End (move to next sequence)

Step 4. Calculate $\mathbf{P}_{T}^{t_{c c}}$, the transition probability matrix between percentile values by summing up the number of hits for a given $*$ and then for each $* *$ divide $\mathbf{P}_{F}^{t_{c c}}(*, * *)$ by the total sum to get a probability $\mathbf{P}_{T}^{t_{c c}}(*, * *)$

$$
\mathbf{P}_{T}^{t_{c c}}(*, * *)=\frac{\mathbf{P}_{F}^{t_{c c}}(*, * *)}{\sum_{f=1}^{n} \mathbf{P}_{F}^{t_{c c}}(*, f)}
$$

End (move to next $t_{c c}$ ).
[63] The final transition matrix for the SSDP is developed as follows. Consider the set of cumulative indices for the $m_{1}$ member ensemble of reservoir inflows, $D_{t, i}$. As was done in the first steps of phase I, calculate for each member of these time series the $p_{h}$ group for each year $t$ and sequence $i$ by selecting the appropriate index from $P_{h}$ and $D_{t}^{p_{h}}$. The result is a matrix of indices $\mathbf{P}_{C C}(t, i)$. Using this information, the transition matrix for each year is calculated with the following algorithm.

Step 1. For every year $t>2010$ (future sequence)

Step 2. For each member $i$ Look up in $\mathbf{P}_{T}^{t}$ row corresponding to index $\mathbf{P}_{C C}(t, i)$ and then consider all values in that row with indices

$\mathbf{P}_{C C}(t+1, i)($ for $i=1: m)$. Sum them and calculate the weighs of each possible $\mathbf{P}_{C C}(t+1, i)$. The result would be the transition $\mathbf{T} \mathbf{P}_{j^{t+1} / i^{t}}^{t}$ (that is the transition probability of going in year $t+1$ from projection $i$ to projection $j$ ):

$$
\mathbf{T P}_{j^{t+1} / i^{t}}^{t}=\frac{\mathbf{P}_{T}^{t}\left(\mathbf{P}_{C C}(t, i), \mathbf{P}_{C C}(t+1, j)\right)}{\sum_{d=1}^{m_{1}} \mathbf{P}_{T}^{t}\left(\mathbf{P}_{C C}(t, i), \mathbf{P}_{C C}(t+1, d)\right)}
$$

End year $t$.

The result is $\mathbf{T P}_{j^{t+1} / i^{t}}^{t}$ for all $t$ from the beginning of the time series through 2099 and all $i, j$ from $1 \ldots m$, as needed in the SSDP approach developed above.

[64] Acknowledgments. We are gratefully indebted to Michael W. Hanemann, who inspired much of the work presented in this paper. We also wanted to thank an extensive list of colleagues from whom we received useful advice and help: Hugo Salgado, Alan Hamlet, Tariq Kadir, Can Dogrul, Charlie Brush, Beth Faber, Guido Franco, Hicham Eltal, and Dan Pope.

\section{References}

Barnett, T. P., J. C. Adam, and D. P. Lettenmaier (2005), Potential impacts of a warming climate on water availability in snow-dominated regions, Nature, 438, 303-309, doi:10.1038/nature04141.

Brekke, L. D., J. D. Anderson, E. P. Maurer, M. D. Dettinger, E. S. Townsley, A. Harrison, and T. Pruitt (2009), Assessing reservoir operations risk under climate change, Water Resour. Res., 45, W04411, doi:10.1029/2008WR006941.

California Department of Water Resources (2003), California's Groundwater, Bull. 118, Sacramento, Calif.

Cayan, D. R., E. P. Maurer, M. D. Dettinger, M. Tyree, and K. Hayhoe (2008), Climate change scenarios for the California region, Clim. Change, 87, suppl. 1, S21-S42, doi:10.1007/s10584-007-9377-6.

Coe, J. J. (1990), Conjunctive use-Advantages, constraints, and examples, J. Irrig. Drain. Eng., 116, 427-443, doi:10.1061/(ASCE)0733-9437 (1990)116:3(427).

Dessai, S., and M. Hulme (2007), Assessing the robustness of adaptation decisions to climate change uncertainties: A case study on water resources management in the east of England, Glob. Environ. Change, 17, 59-72, doi:10.1016/j.gloenvcha.2006.11.005.

Dettinger, M. D. (2005), From climate change spaghetti to climate change distributions for 21st century, San Francisco Estuary Watershed Sci., 3, $1-14$.

Dettinger, M. D., D. R. Cayan, M. Meyer, and A. E. Jeton (2004), Simulated hydrologic responses to climate variations and change in the Merced, Carson, and American river basins, Sierra Nevada, California, 19002099, Clim. Change, 62, 283-317, doi:10.1023/B:CLIM.0000013683. $13346.4 \mathrm{f}$. 
Faber, B. A. (2000), Real-time reservoir optimization using ensemble streamflow forecasts, Ph.D. thesis, Cornell Univ., Ithaca, N. Y.

Faber, B. A., and J. R. Stedinger (2001), Reservoir optimization using sampling SDP with ensemble streamflow prediction (ESP) forecasts, J. Hydrol., 249, 113-133, doi:10.1016/S0022-1694(01)00419-X.

Georgakakos, K. P., N. E. Graham, T. M. Carpenter, A. P. Georgakakos, and H. Yao (2005), Integrating climate-hydrology forecasts and multiobjective reservoir management for northern California, Eos Trans. $A G U, 86(12)$, doi:10.1029/2005EO120002.

Hayhoe, K., et al. (2004), Emissions pathways, climate change, and impacts on California, Proc. Natl. Acad. Sci. U. S. A., 101, 12,42212,427, doi:10.1073/pnas.0404500101.

Hazen, A. (1914), Storage to be provided in impounding reservoirs for municipal water supply, Trans. Am. Soc. Civ. Eng., 77, 1539-1640.

Johnson, S. A., J. R. Stedinger, C. A. Shoemaker, Y. Li, and J. A. TejadaGuibert (1993), Numerical solution of continuous-state dynamic programs using linear and spline interpolation, Oper. Res., 41, 484-500, doi:10.1287/opre.41.3.484.

Kelman, J., J. R. Stedinger, L. A. Cooper, E. Hsu, and S. Yuan (1990), Sampling stochastic dynamic programming applied to reservoir operation, Water Resour. Res., 26, 447-454.

Klemes, V. (1987), One hundred years of applied storage reservoir theory, Water Resour. Manage., 1, 159-175, doi:10.1007/BF00429941.

Klemes, V. (2000), Design implications of climate change, in Common Sense and Other Heresies: Selected Papers on Hydrology and Water Resources Engineering, pp. 227-239, Can. Water Resour. Assoc., Cambridge, Ont., Canada.

Labadie, J. W. (2004), Optimal operation of multireservoir systems: Stateof-the-art review, J. Water Resour. Plann. Manage., 130, 93-111, doi:10.1061/(ASCE)0733-9496(2004)130:2(93).

Lee, J.-H., and J. W. Labadie (2007), Stochastic optimization of multireservoir systems via reinforcement learning, Water Resour. Res., 43, W11408, doi:10.1029/2006WR005627.

Lee, S. Y., A. F. Hamlet, C. J. Fitzgerald, S. J. Burges, and D. P. Lettenmaier (2006), Optimized flood control in the Columbia River Basin for a global warming scenario, in Operating Reservoirs in Changing Conditions, edited by D. Zimbelman and W. C. Loehlein, pp. 256-271, Am. Soc. of Civ. Eng., Reston, Va.

Maurer, E. P. (2007), Uncertainty in hydrologic impacts of climate change in the Sierra Nevada, California, under two emissions scenarios, Clim. Change, 82, 309-325, doi:10.1007/s10584-006-9180-9.

Maurer, E. P., and P. B. Duffy (2005), Uncertainty in projections of streamflow changes due to climate change in California, Geophys. Res. Lett., 32(3), L03704, doi:10.1029/2004GL021462.

Medellin-Azuara, J., J. Harou, M. Olivares, J. Lund, R. Howitt, S. Tanaka, M. Jenkins, K. Madani, and T. Zhu (2006), Climate warming and water supply management in California, Rep. CEC-500-2005-195-SF, Calif. Energy Comm., Sacramento, Calif.

Medellin-Azuara, J., J. Harou, M. Olivares, K. Madani, J. Lund, R. Howitt, S. Tanaka, M. Jenkins, and T. Zhu (2008), Adaptability and adaptations of California's water supply system to dry climate warming, Clim. Change, 87, suppl. 1, S75-S90, doi:10.1007/s10584-007-9355-Z.

Milly, P. C. D., J. Betancourt, M. Falkenmark, R. M. Hirsch, Z. W. Kundzewicz, D. P. Lettenmaier, and R. J. Stouffer (2008), Stationarity is dead: Whither water management, Science, 319, 573-574, doi:10.1126/ science. 1151915.
Pierce, D. W., T. P. Barnett, B. D. Santer, and P. J. Gleckler (2009), Selecting global climate models for regional climate change studies, Proc. Natl. Acad. Sci. U. S. A., 106, 8441-8446.

Rippl, W. (1883), The capacity of storage reservoirs for water-supply, Minutes Proc. Inst. Civ. Eng., 71, 270-278.

Tanaka, S. K., T. Zhu, J. R. Lund, R. E. Howitt, M. W. Jenkins, M. A. Pulido, M. Tauber, R. S. Ritzema, and I. C. Ferreira (2006), Climate warming and water management adaptation for California, Clim. Change, 76, 361-387, doi:10.1007/s10584-006-9079-5.

Timmermann, A., J. Oberhuber, A. Bacher, M. Esch, M. Latif, and E. Roeckner (1999), Increased El Niño frequency in a climate model forced by future greenhouse warming, Nature, 398, 694-696, doi:10.1038/19505.

Turgeon, A. (2007), Stochastic optimization of multireservoir operation: The optimal reservoir trajectory approach, Water Resour. Res., 43, W05420, doi:10.1029/2005WR004619.

Van Rheenen, N. T., A. W. Wood, R. N. Palmer, and D. P. Lettenmaier (2004), Potential implications of PCM climate change scenarios for Sacramento-San Joaquin River Basin hydrology and water resources, Clim. Change, 62, 257-281, doi:10.1023/B:CLIM.0000013686. 97342.55 .

Vedula, S., and D. N. Kumar (1996), An integrated model for optimal reservoir operation for irrigation of multiple crops, Water Resour. Res., 32, 1101-1108, doi:10.1029/95WR03110.

Vicuna, S. (2007), Adaptation to climate change impacts on California water resources, Ph.D. thesis, 256 pp., Univ. of Calif., Berkeley.

Vicuna, S., and J. A. Dracup (2007), The evolution of climate change impact studies on hydrology and water resources in California, Clim. Change, 82, 327-350, doi:10.1007/s10584-006-9207-2.

Yakowitz, S. (1982), Dynamic programming applications in water resources, Water Resour. Res., 18, 673-696, doi:10.1029/WR018i004p00673.

Yao, H., and A. Georgakakos (2001), Assessment of Folsom Lake response to historical and potential future climate scenarios: 2. Reservoir management, J. Hydrol., 249, 176-196, doi:10.1016/S0022-1694(01)00418-8.

Yeh, W. W. G. (1985), Reservoir management and operations modelsA state-of-the-art review, Water Resour. Res., 21, 1797-1818, doi:10.1029/WR021i012p01797.

L. L. Dale, Environmental Energy Technologies Division, Lawrence Berkeley National Laboratory, 1 Cyclotron Rd., MS 90-4000, University of California, Berkeley, CA 94720, USA. (1ldale@lbl.gov)

J. A. Dracup, Department of Civil and Environmental Engineering, University of California, 625 Davis Hall, Rm. 1710, Berkeley, CA 94720-1710, USA. (dracup@ce.berkeley.edu)

J. R. Lund, Civil and Environmental Engineering Department, University of California, 1 Shields Ave., Davis, CA 95616, USA. (jrlund@ucdavis. edu)

E. P. Maurer, Civil Engineering Department, Santa Clara University, 500 El Camino Real, Santa Clara, CA 95053-0563, USA. (emaurer@engr.scu. edu)

S. Vicuna, Centro Interdisciplinario de Cambio Global UC, Pontificia Universidad Católica de Chile, Av. Vicuña Mackenna 4860, Santiago 6904411, Chile. (svicuna@uc.cl) 